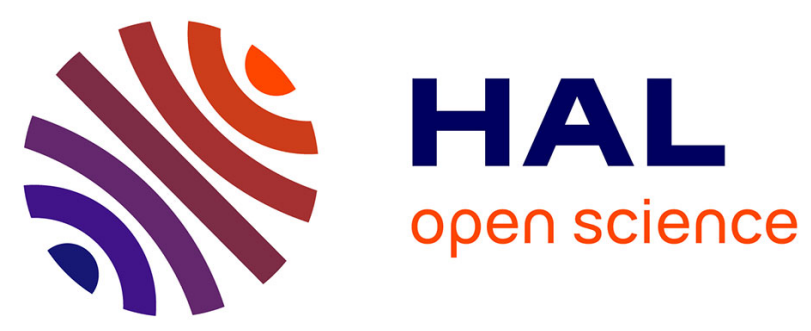

\title{
Thermo-mechanical fatigue behaviour of welded tubular parts made of ferritic stainless steel
}

\author{
Marie-Cécile Robin, Denis Delagnes, Roland E. Logé, Pierre-Olivier
}

Bouchard, Stéphanie da Costa, Mauricio Monteagudo-Galindo, Vincent Velay

\section{- To cite this version:}

Marie-Cécile Robin, Denis Delagnes, Roland E. Logé, Pierre-Olivier Bouchard, Stéphanie da Costa, et al.. Thermo-mechanical fatigue behaviour of welded tubular parts made of ferritic stainless steel. International Journal of Fatigue, 2013, 54, pp.84 - 98. 10.1016/j.ijfatigue.2013.04.004 hal-01398870

\author{
HAL Id: hal-01398870 \\ https://hal.science/hal-01398870
}

Submitted on 17 Nov 2016

HAL is a multi-disciplinary open access archive for the deposit and dissemination of scientific research documents, whether they are published or not. The documents may come from teaching and research institutions in France or abroad, or from public or private research centers.
L'archive ouverte pluridisciplinaire $\mathbf{H A L}$, est destinée au dépôt et à la diffusion de documents scientifiques de niveau recherche, publiés ou non, émanant des établissements d'enseignement et de recherche français ou étrangers, des laboratoires publics ou privés. 


\title{
Thermo-mechanical fatigue behaviour of welded tubular parts made of ferritic stainless steel.
}

\author{
M.-C. Robin ${ }^{\mathrm{a}}$, D. Delagnes ${ }^{\mathrm{b}}$, R. Logéc ${ }^{\mathrm{c}}$ P.-O. Bouchard ${ }^{\mathrm{c}}$, S. Da Costa ${ }^{\mathrm{d}}, \mathrm{M}$. \\ Monteagudo-Galindo ${ }^{\mathrm{d}}$, V. Velay ${ }^{\mathrm{b}}$ \\ ${ }^{a}$ AREVA NP - BU FUEL - 14 rue Juliette Récamier 69006 Lyon - France \\ ${ }^{b}$ Université de Toulouse - Mines Albi - INSA, UPS, ISAE, ICA (Institut Clément Ader) - \\ Campus Jarlard - 81013 Albi - Cedex 09 - France. \\ ${ }^{c}$ MINES ParisTech, Ctr Mat Forming CEMEF, UMR CNRS 7635, F-06904 Sophia Antipolis, \\ France. \\ ${ }^{d}$ Faurecia Emissions Control Technologies - $R \& 3$ D center - Bois sur prés - 25550 Bavans -
}

France.

\begin{abstract}
Car exhaust manifolds are critical components subjected to cyclic thermo-mechanical fatigue (TMF) during function. To reduce design costs, robust numerical design tools are required to assess their behaviour and lifetime. Manifolds are constructed by welding several ferritic stainless steel tubular parts together. TMF behaviour of a 1.4509 steel in welded and unwelded conditions is assessed under various loading conditions. Unified elasto-viscoplastic constitutive laws are developed. The specific thermo-mechanical behaviour of the heat-affected zone (HAZ) is also taken into account for welded steel. The reliability of the proposed models in predicting the mechanical response, in particular in the welded zone, is investigated. The local strains of the welded area are measured using a digital image correlation technique. Hence, several numerical models are implemented in ABAQUS and different areas are analysed to reproduce the mechanical behaviour of the heat-affected zone. Results are discussed and compared with experiments to validate the proposed model of the mechanical response of a welded component.
\end{abstract}

Keywords: Thermo-mechanical fatigue, Cyclic behaviour modelling, Welded

\footnotetext{
Email addresses: marie-cecile.robin-boudaoud@areva.com (M.-C. Robin), denis.delagnes@mines-albi.fr (D. Delagnes), roland.loge@mines-paristech.fr (R. Logé), pierre-olivier.bouchard@mines-paristech.fr (P.-O. Bouchard), stephanie.dacosta@faurecia.com (S. Da Costa), mauricio.monteagudo-galindo@faurecia.com (M. Monteagudo-Galindo), vincent.velay@mines-albi.fr (V. Velay)
} 
component, Digital image correlation

\section{Introduction}

Many industrial components undergo severe thermo-mechanical loading in service or during start-up/shut-down operations. Measurements of thermo-mechanical strains and stresses on real components is very difficult or impossible. Therefore, they must be estimated by relevant thermo-mechanical constitutive laws. Due to their complicated geometry and their substantial size, car manifolds are often not made of one piece of material but of several components welded together. These components are damaged by low cycle thermo-mechanical fatigue and fatigue cracks usually appear in welded zones. In general, the lifetime reduction of welded components is attributed to geometrical discontinuities [1] and to the mismatch between thermo-mechanical behaviour of the base metal, the heat-affected zone (HAZ) and the weld metal [2]. Behaviour mismatch induces local strain concentration in lower yielding zones [3] and complex local triaxial loadings [4]. In general, the mechanical stress and strain distribution at half life (stabilised cycle) is used as a baseline lifetime estimation under isothermal or non-isothermal low cycle fatigue [5]. This stress/strain distribution also depends on initial residual stresses and their evolution while cycling $[6,7,8]$. Direct achievement by measurements of the mechanical field distribution, in particular at half life, is not possible. Numerical simulations are the only relevant ways to access these thermo-mechanical parameters. Such simulations require relevant and well-examined constitutive laws describing thermo-mechanical behaviour. HAZ and weld metal can be assimilated to zones exhibiting a gradient in terms of thermo-mechanical properties. It is therefore necessary to identify relevant models for each constituent of the "gradient material" of the weld zone. The model formulation can be based on several constitutive equations formulated within the theoretical framework of thermodynamics of irreversible processes $[9,10]$. This theory assumes that the evolution of a material system can be described as a succession of equilibrium states. It introduces two sets of variables. The observable (such as total strain or temperature) and the internal (intended to describe internal material evolution) variables allow a material element and its evolution over time 
and temperature to be defined completely. In the classical viscoplastic theory, total strain can be partitioned into elastic and inelastic strains. The model equations were determined from the free energy potential used to define the state laws and from the dissipation potential used to define the evolution equations. Many works investigated such kinds of approaches in order to develop behaviour models for metallic materials used in various industrial applications $[5,11,12,13]$. Microstructures of HAZ and weld metal depend on the thermal cycles undergone by each part during welding operations. HAZ and welded metal are therefore composed of multiple materials. It has been reported that from a good knowledge of weldment metallurgy, it is possible to realistically represent its behaviour with several models using, for instance, a variable yield stress based on hardness measurements in various zones of the weld [14]. In the literature, these models are identified from fatigue test results performed on specimen shapes similar to industrial components [4] or obtained by appropriate heat treatments [15]. Macroscopic mechanical models used are known to be cost effective $[16,17,18]$.

In this study, the aim is to develop and validate a methodology for modelling the mechanical response of welded zones of a stainless ferritic steel for car manifold applications. This is a first step toward lifetime prediction of this component. An alternative experimental method was proposed to characterise mechanical behaviour of the welded zones. Specimens with microstructures very similar to the base metal and melted metal were used. Isothermal cyclic tension compression tests, covering the complete in-service temperature range, were conducted on two types of specimens: one for characterising the base metal behaviour and another for the melted metal behaviour. Behaviour of the heat-affected zone was deduced from the analysis of the base metal and weld metal behaviours, according to the results provided by the different thermo-mechanical tests and to metallurgical observations. Based on these experiments, an elasto-viscoplastic model with nonlinear kinematic and isotropic hardening components [9] was identified for each material constituting the welded zone. Thermo-mechanical tests were performed on the base metal specimens to assess the predictive capability of the model for exhaust manifold application. Serious effort was made to assess the relevance of our method in 
representing weld behaviour. A traction-compression test under total strain control on a welded specimen was carried out, measuring the strain distribution with the digital image correlation (DIC) technique. In this way, the strain distribution could be monitored while cycling $[19,20]$ and the results of this test were compared to numerical simulations. Several finite element (FE) calculations were conducted to investigate the influence of the considered behaviour models in the different areas and the impact of the shape of these areas. Hence, a better understanding of the behaviour mismatch effect on the stabilised mechanical response is possible.

\section{Experimental procedures}

\subsection{Materials}

\subsubsection{Filler and base metal composition}

The base material investigated in this study is a stainless ferritic steel. The composition of the X2CrTiNb18 is given in Table 1. It is a low carbon steel with a high chromium content. The body-centred cubic structure is stable until melting. At high temperature, however, precipitation of Laves phase containing $\mathrm{Nb}\left(\mathrm{Fe}_{2} \mathrm{Nb}\right)$ is likely to happen and is known to have a beneficial effect on creep resistance [18]. Its high corrosion resistance, low cost and stability at high temperature make this steel particularly well-suited for high temperature applications. The filler material is $\mathrm{X} 3 \mathrm{CrNb} 17$. Its chemical composition is given in Table 1. Changes were compared to the base material composition.

\begin{tabular}{ccccccccc}
\hline & $C$ & $S i$ & $M n$ & $P$ & $S$ & $C r$ & $N b$ & $T i$ \\
\hline Filler Metal & 0.05 & 1 & 1 & 0.04 & 0.015 & 16 to 18 & $<1$ & - \\
Base Metal & 0.03 & 1 & 1 & 0.04 & 0.015 & 17.5 to 19.5 & $<1$ & 0.1 to 0.6 \\
\hline
\end{tabular}

Table 1: Chemical composition in weight \%

\subsubsection{Welded zone microstructure}

The welding operation usually leads to complex microstructures in the welded zone, where three main domains can be identified: melted metal, heat-affected zone (HAZ), and base metal. HAZs adjacent to the base metal are heated to a high 
temperature (although lower than its melting point) and allowed to cool down fairly rapidly. Depending on the welding process and the microstructural stability of the base metal, the mechanical properties and the microstructure of HAZs are more or less affected. For instance, in a $9 \mathrm{Cr} 1 \mathrm{MoNbV}$ weldment, the HAZ was found to be composed of three sub-zones: coarse-grained austenite, fine-grained austenite and partially transformed austenite martensitic structure [21]. In this steel, during welding, the HAZ is exposed to thermal recovery and grain growth as sole phenomena. The metallographic investigations revealed that the microstructure of the HAZ is very similar to the initial state of the base metal. The melted metal is composed of coarse equiaxed grains and long equiaxed grains. Figure 1 illustrates the investigated welding cross section of car exhaust manifolds where the three domains described previously can be observed.

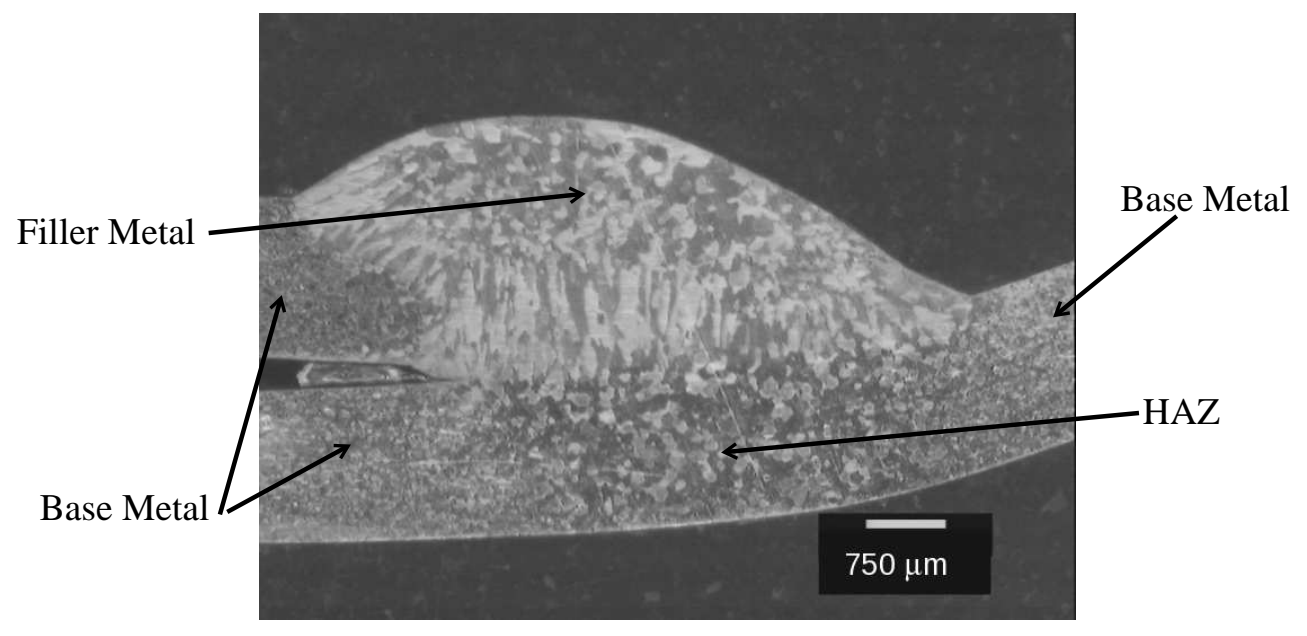

Figure 1: Typical welded zone of car exhaust manifolds

\subsection{Specimens}

Since the metallurgy of the HAZ is close to that of the base metal, specimens were designed for identifying the mechanical behaviour of either the base metal or the melted metal. Consequently, the analysis of both mechanical behaviours will allow HAZ behaviour to be deduced. No standardised procedure exists for studying the local behaviour of a welded joint specimen. Most of the studies are dedicated to the behaviour analysis of weldments encountered in nuclear plants. These weldments 
are often large enough to allow for cutting specimens or micro-specimens from the actual industrial component. Different sampling methods are used according to the authors. Readers should refer to the following article for an overview [2]. When the different zones are not large enough, appropriate heat treatments are usually attempted in order to reproduce their structure [15]. Even though this method is interesting, it is time consuming, and may lead to some artefacts. It was impossible to remove specimens from a manifold and the objective was to identify the weld behaviour via a fast procedure. Consequently, an innovative method was set up. Tubular base metal specimens (hereafter mentioned as type I specimens) with an external diameter of $16 \mathrm{~mm}$ and a thickness of $2 \mathrm{~mm}$ were removed from a tube similar to that used for an actual manifold. These specimens presented the following specific requirements for matching industrial tubes: similar grain size and surface finishing as well as pre-strain hardening due to the forming of the industrial tubes. The specimens were expected to present a yield strength similar to that of industrial components. This is a key point since it has been shown that the ratio of the yield strengths of welded metal and base metal has a significant impact on fatigue life [22]. Figure 2 presents the micro structure of the welded specimen. As shown in figure 1, the three domains can be observed (Base Metal, Filler Metal and HAZ). Moreover, some hardness measurements were performed at different depth $\mathrm{X}$ from the outer surface of the specimen. Figure 2 provides a profile at $X=0.4 \mathrm{~mm}$ depth, the hardness of the base metal is expected to be close to $200 \mathrm{Hv}$ whereas the hardness of the HAZ provides a measurement less than $190 \mathrm{Hv}$. Thus, an assessment of the size of the HAZ can be done.

Melted metal specimens (type II) were made according to the following procedure: in a base metal tube, a $14 \mathrm{~mm}$ wide groove was machined and filled with metal by using the gas metal arc welding process, under the same welding parameters as those of industrial conditions. The weld joint was then erased to obtain equivalent geometry to the base metal specimens. Thanks to the initial groove, coaxiality over the entire tube was kept even after welding. Almost the entire $14 \mathrm{~mm}$ zone was composed of melted metal that represents a welded region in a real manifold at the end. This procedure is acceptable since the microstructures of filler metal and base 

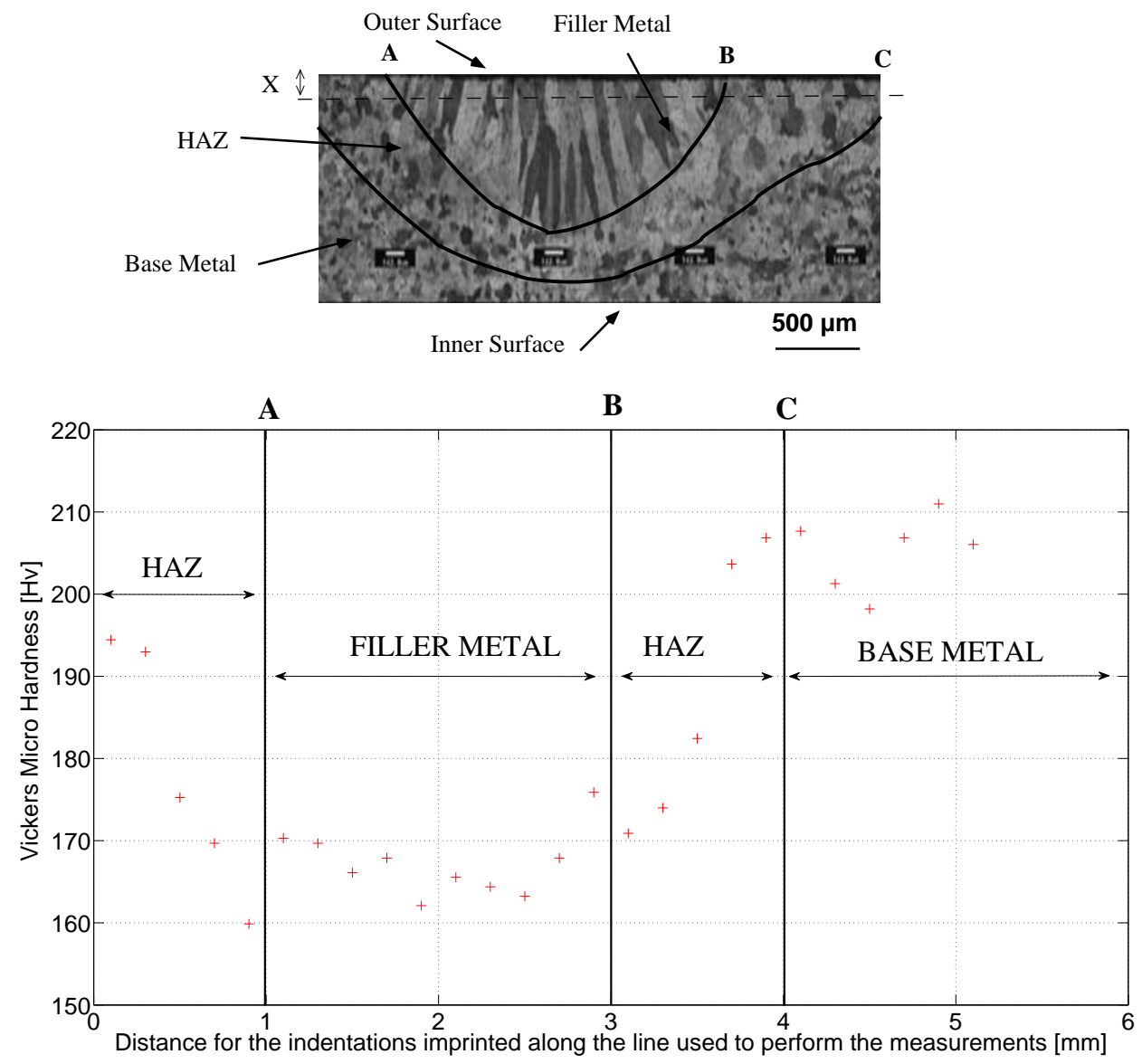

Figure 2: Microstructure and Hardness measurements performed on the welded zone of the fatigue specimen at a depth of $\mathrm{X}=0.4 \mathrm{~mm}$ from the outer surface. 
metal are close; it allows the melted zones to be characterised quite easily (see Fig. 3).

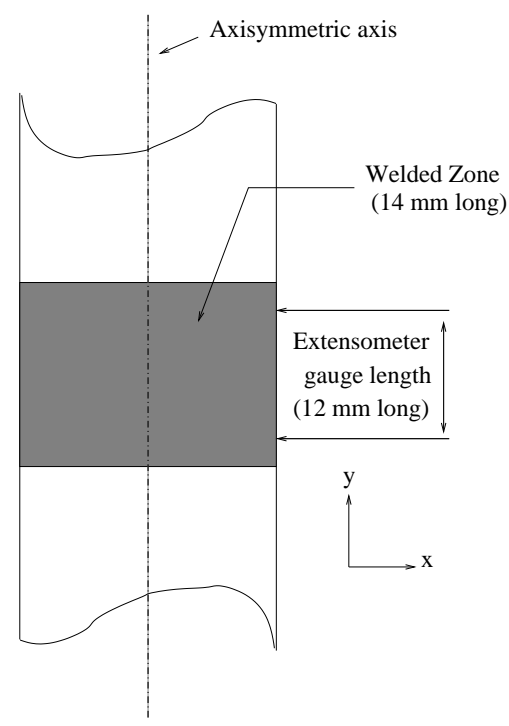

Figure 3: Representative welded material (type II specimen)

\subsection{Test procedure and test plan}

Low cycle fatigue tests under total strain control were performed on the two types of specimens, with a closed loop Schenck Hydropuls $250 \mathrm{kN}$ servo-hydraulic testing machine. Heating of samples was achieved with an induction coil. Strain was recorded with a $10 \mathrm{~mm}$ gauge length extensometer with alumina rods. The temperature test range was $20^{\circ} \mathrm{C}$ to $900^{\circ} \mathrm{C}$, covering the in-service temperature range of a car manifold. For type II specimens, the two extensometer rods were placed in the groove. The response of the welded metal was then monitored. The procedure of the low cycle cycle fatigue test was based on those developed by Zhang [23] and Velay [24]. For each temperature, one specimen was subjected to different sequences of strain cycles showing the main characteristics of the mechanical behaviour: cyclic hardening/softening, kinematic hardening, and viscous effect. For each specimen and each temperature level, the first part of the procedure included push-pull tests with a strain range of $1 \%$ from the first to the stabilised cycle. Afterwards, cycles with four strain rates varying from $10^{-4}$ to $2.10^{-2} s^{-1}$ were performed in order to investigate the strain rate sensitivity of the materials. Lastly, cycles including tensile 
dwell time were conducted. They exhibited a stress relaxation increase with the test temperature. For this procedure, numerical identification of the constitutive parameters described in section 4 was performed. This procedure was used for seven temperature levels between $20^{\circ} \mathrm{C}$ and $900^{\circ} \mathrm{C}$.

Moreover, thermo-mechanical tests were carried out with the same equipment. TMF tests were only conducted on base metal specimens and were performed under mechanical strain and temperature control, with triangular signal input. Real-time thermal strain compensation was achieved using a linear thermal strain temperature relationship in the form $\epsilon_{t h}=\lambda T+\mu$. Coefficients $\lambda$ et $\mu$ were determined during thermal tests under zero load prior to the test campaign [23].

Finally, strain distribution was measured with a 3D digital image correlation (DIC) technique based on both DIC and stereovision [25, 26]. This technique uses an algorithm in order to determine the point correspondences between two images of a specimen obtained by two rigidly fastened cameras. It basically consists in constructing a 3D object, in our case the zone of interest of the tubular sample, from a pair of images. After a required preliminary calibration stage and the determination of the 3D relative positioning/orientation of the two cameras, the 3D specimen shape could be reconstructed from the point correspondences using triangulation (see Fig. 4). Hence, to determine the 3D displacement field, DIC is used to evaluate point correspondences between the stereo pairs acquired before and after deformation. This technique was implemented with the assistance of Vic-3D commercial software [27].

To observe the specimen while deforming, it was necessary to remove induction coil. Tests were therefore performed at room temperature. 3D displacements and $2 \mathrm{D}$ strain fields were computed by comparing a pair of images at time $t$ to a pair of images at the time of reference. In order to capture appropriate DIC images, a randomly distributed paint pattern was laid on the side of the specimen as shown in Fig. 4. Details of the 3D DIC software are available in the literature (for instance, see $[19,20])$. 


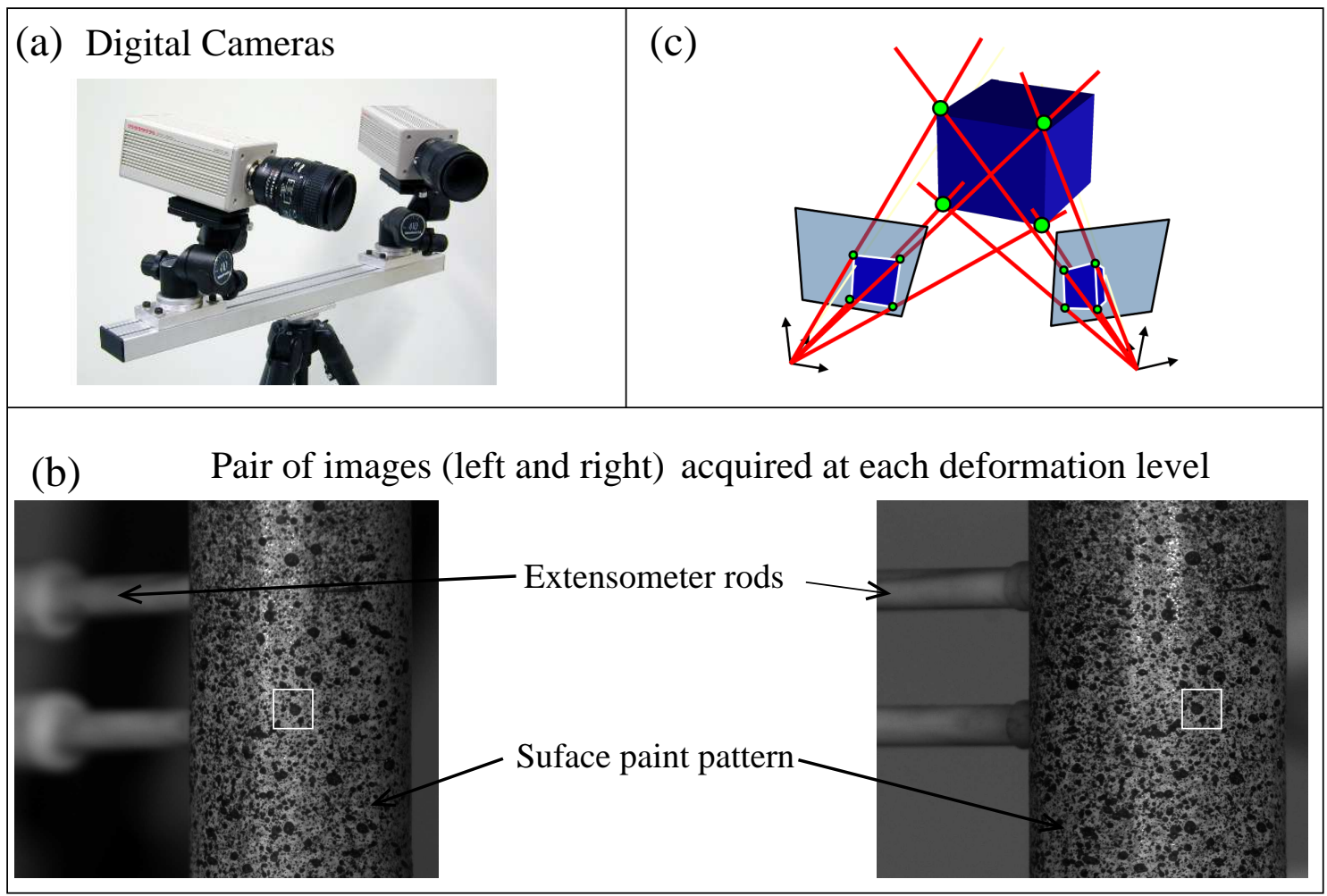

Figure 4: Digital Image Correlation technique: (a) Stereo-rig composed of two digital cameras, (b) 3D displacement field determination by a pair of images and Surface preparation with a randomly distributed paint pattern, (c) Reconstruction of the 3D specimen shape from the points correspondences using triangulation 


\section{Experimental results}

\subsection{Base metal}

The base metal exhibited cyclic softening during the first hundred cycles. Thereafter, its cyclic behaviour was stable until cracking appeared in the specimen. Figure 5 illustrates this phenomenon, the normalized stress amplitude is the ratio between the stress amplitude obtained at each cycle over the stress amplitude measured at the first cycle of the test performed at $\mathrm{T}=20 \mathrm{C}$. Cyclic softening was significant at $20^{\circ} \mathrm{C}$ and continuously decreased with temperature. This latter effect was due to the thermally activated recovery of strain hardening. It was previously introduced during the forming operations. Moreover, the strain rate effect was significant at temperatures higher than $600^{\circ} \mathrm{C}$, and was not observed for lower temperatures. Figure 6 illustrates the stress-strain response for the stabilised cycle and different strain rates at $T=900^{\circ} \mathrm{C}$.

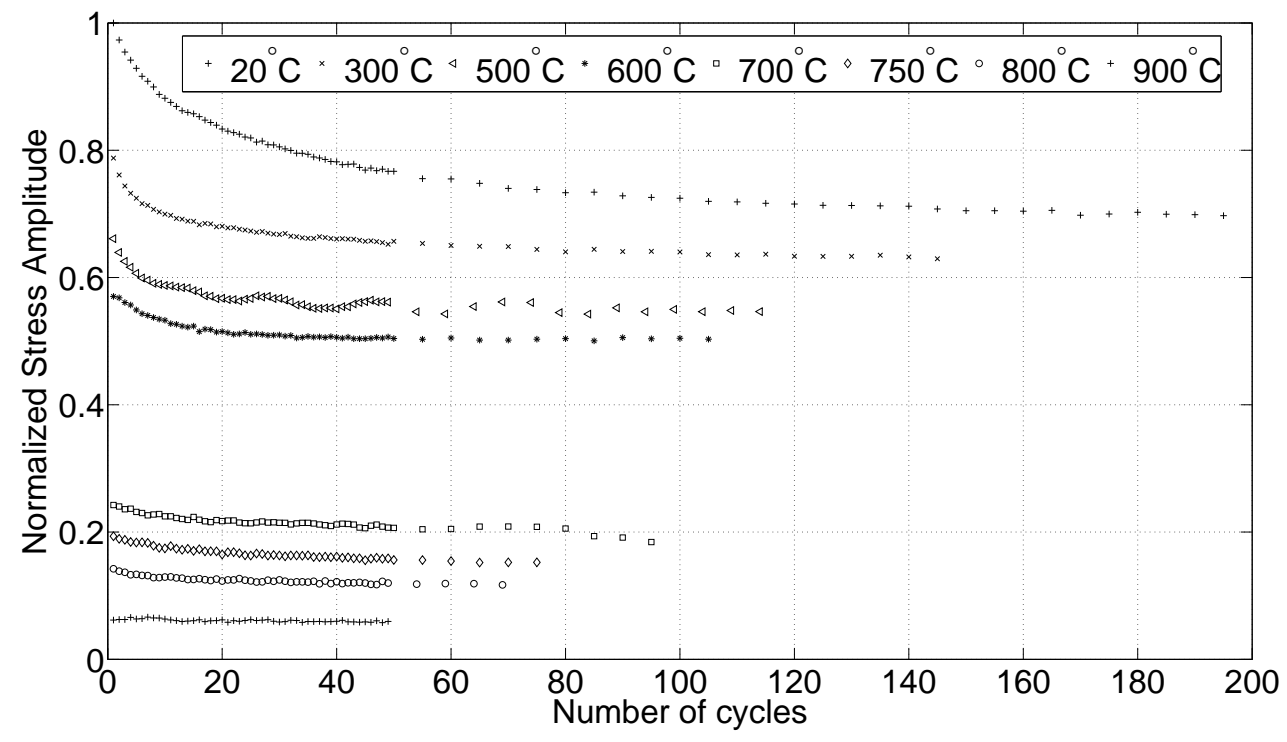

Figure 5: Base metal cyclic softening (type I specimen)

\subsection{Cyclic behaviour of the filler metal}

The welded metal exhibited cyclic hardening during the first cycles. Its cyclic behaviour was saturated in a very short time (see Fig. 7). The definition of the normalized stress amplitude is the same as the one used for the base metal specimen. 


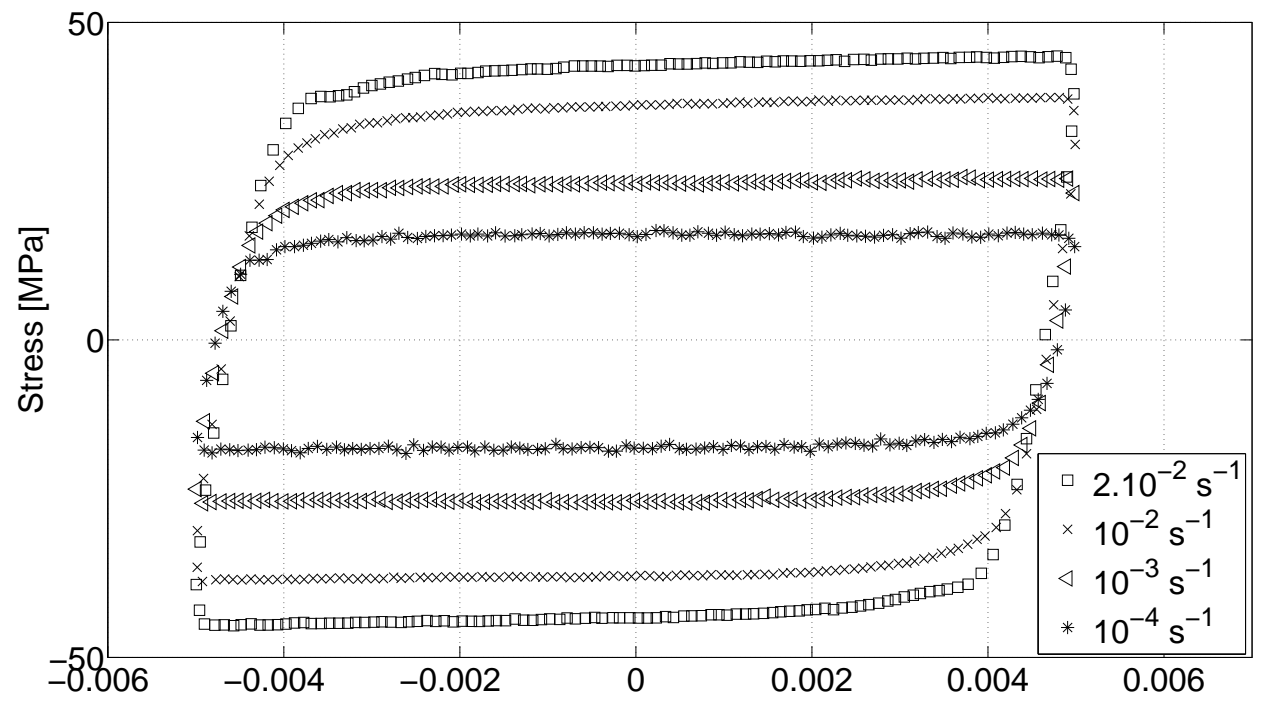

Figure 6: Strain rate effect at $900^{\circ} \mathrm{C}$ for type I specimen

At any test temperature and strain amplitude, the saturated stress level was lower in the melted metal than in the base metal. As for the base metal, the mechanical response of the welded metal was sensitive to the strain rate at temperatures higher than $600^{\circ} \mathrm{C}$ as shown, in the sequel, for a temperature of $700^{\circ} \mathrm{C}$ (figure 11).

\section{Mechanical behaviour modelling}

\subsection{Isothermal fatigue tests}

According to the experimental behaviour described in section 3, a description of the cyclic behaviour of the weld and base metal with an elasto-viscoplastic model developed by Chaboche [9] was proposed. During the last few decades, this model was improved extensively to better describe creep-fatigue interaction, inverse rate sensitivity [11], multiaxial ratchetting [28] or time recovery effects [16].

The formulation chosen here is the following. The elastic domain can be written as follows:

$$
f=J(\underline{\sigma}-\underline{X})-R<0
$$

where $\underline{\sigma}$ is the Cauchy stress tensor. $R$ is an isotropic variable which represents 


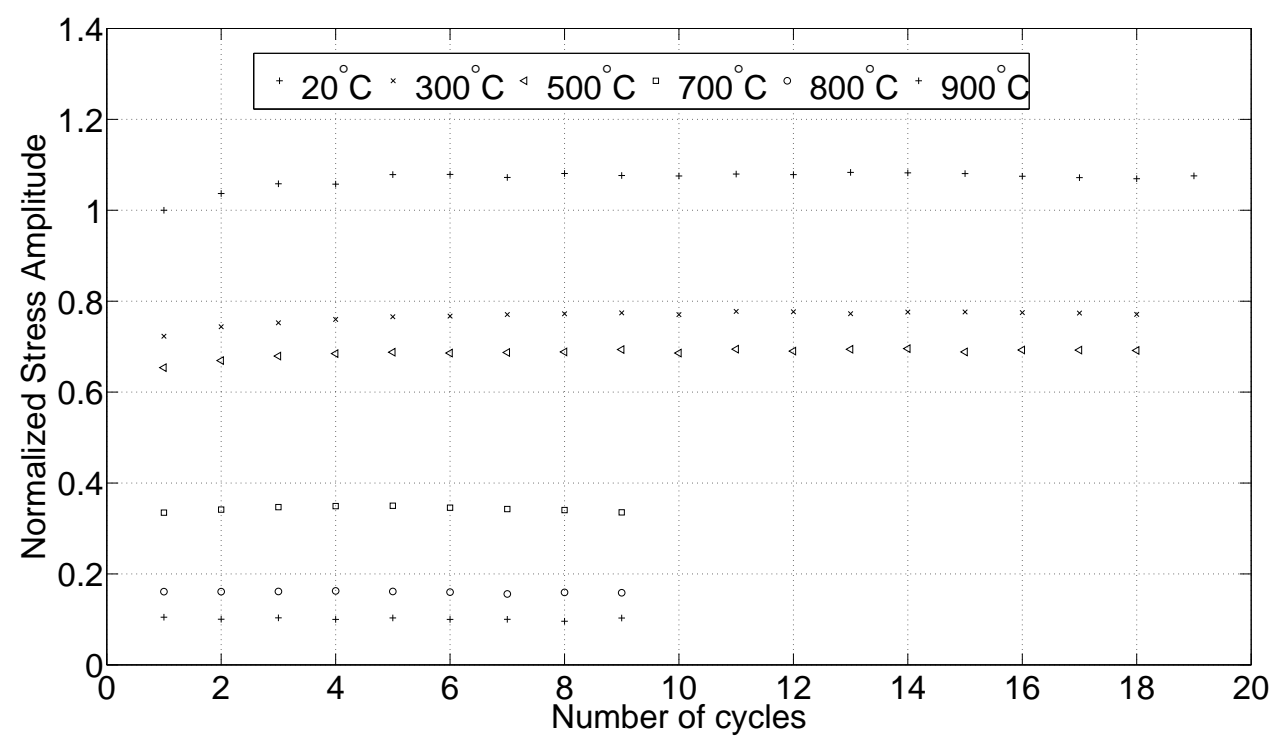

Figure 7: Welded metal cyclic behaviour

the change of the size of the initial elastic domain, given by $R_{0}$, while cycling. In the case of the base metal, it is decomposed into two main mechanisms, $R=$ $R_{0}+\sum_{i=1}^{2} R_{i}$, to dissociate the first fast softening phase and the second slow softening phase. In the case of the weld metal, a constant isotropic variable is considered $R=R_{0}$.

The evolution law of each $R_{i}$ is given by:

$$
R_{i}=Q_{i}(T)\left(1-\exp \left(-b_{i}(T) p\right)\right)
$$

where $p$ is the cumulative plastic strain, and $Q_{i}(T), b_{i}(T)$ are material parameters that need to be identified.

The kinematic variable $\underline{X}$ is linearly related to the internal variable $\underline{\alpha}$, which characterises the internal strain mismatch coming from the plastic straining. Like $R, \underline{X}=\sum_{i=1}^{2} \underline{X_{i}}$ is also decomposed into two terms, with evolution laws given by:

$$
\underline{X_{i}}=\frac{2}{3} C_{i}(T) \underline{\alpha_{i}} \quad \text { with } \quad \underline{\alpha_{i}}=\underline{\dot{\varepsilon}}_{p}-D_{i} \underline{\alpha_{i}} \dot{p}
$$

$\dot{p}$ is the norm of the plastic strain rate $\underline{\epsilon}_{p}$ : 


$$
\dot{p}=\frac{2}{3} J\left(\underline{\dot{\varepsilon}}_{p}\right)=\sqrt{\frac{2}{3} \dot{\varepsilon}_{p}: \underline{\dot{\varepsilon}}_{p}}
$$

It is time dependent to take into account the viscous effect:

$$
\dot{p}=\left\langle\frac{f}{K(T)}\right\rangle^{n(T)}
$$

The set of parameters $\left\{b_{i} ; Q_{i} ; C_{i} ; D_{i} ; R_{i} ; R_{0}, K ; n\right\}$ was identified for each test temperature, using the $\mathrm{SiDoLo}^{T M}[29]$ optimisation software.

The identification procedure was performed for each material (welded or not) and for each temperature level. In the first step, the parameters of the kinematic component were identified. The stabilised cycles were used in order to identify the values of the first variable $\underline{X_{1}}$ through the parameters $C_{1}$ and $D_{1}$ which described rapid saturation with plastic deformation whereas the second variable $\underline{X_{2}}$, through the parameters $C_{2}$ and $D_{2}$, exhibited a slower evolution. At this stage, the value of the elastic limit of the stabilised cycle was also estimated. Then, the stabilised cycles with different strain rates allowed the viscous parameters $K$ and $n$ to be determined. Last, in the case of the base metal specimen, the elastic limit of the stabilised cycle was replaced by the evolution of the isotropic component assessed using the first sequence of the test (cyclic softening). It showed a fast softening occurring during the first cycles (parameters $Q_{1}$ and $b_{1}$ ) followed by a linear softening until stabilisation (parameters $Q_{2}$ and $b_{2}$ ). At this stage, the initial elastic limit of the base material $R_{0}$ was calibrated. Table 2 provides the parameter values of the behaviour model for the type I specimen. In the case of the welded specimens, the isotropic hardening was assumed to be constant $\left(R=R_{0}\right)$; see Table 3 .

Figures 8, 9, 10 and 11 illustrate the identification results by comparing the experimental tests to the model response. 


\begin{tabular}{|c|c|c|c|c|c|c|c|c|}
\hline & $20^{\circ} \mathrm{C}$ & $300^{\circ} \mathrm{C}$ & $500^{\circ} \mathrm{C}$ & $600^{\circ} \mathrm{C}$ & $700^{\circ} \mathrm{C}$ & $750^{\circ} \mathrm{C}$ & $800^{\circ} \mathrm{C}$ & $900^{\circ} \mathrm{C}$ \\
\hline$E(\mathrm{GPa})$ & 202 & 170 & 153.6 & 128 & 115 & 104 & 93.5 & 65 \\
\hline$R_{0}(\mathrm{MPa})$ & 355 & 260 & 210 & 152 & 39 & 32 & 23 & 2 \\
\hline$K(\mathrm{MPa})$ & 87 & 96.5 & 110 & 140 & 131 & 117 & 104 & 93.5 \\
\hline$n$ & 26.8 & 26.7 & 25 & 21 & 7.4 & 6 & 5 & 4.45 \\
\hline$C_{1}(\mathrm{MPa})$ & 178380 & 130000 & 90000 & 72595 & 44830 & 38000 & 29050 & 4680 \\
\hline$D_{1}$ & 2000 & 2000 & 2000 & 2000 & 2000 & 2000 & 2000 & 2000 \\
\hline$C_{2}(\mathrm{MPa})$ & 31600 & 21900 & 14075 & 11000 & 2410 & 1240 & 600 & 400 \\
\hline$D_{2}$ & 200 & 200 & 200 & 200 & 200 & 200 & 200 & 200 \\
\hline$b_{1}$ & 1.61 & 1.36 & 1.36 & 1.36 & 1.36 & 1.36 & 1.36 & 1.36 \\
\hline$Q_{1}(\mathrm{MPa})$ & -106 & -27 & -7.7 & -8 & -10 & -12 & -8 & -2 \\
\hline$b_{2}$ & 15.9 & 13.8 & 12.9 & 12.1 & 7.7 & 7.7 & 7.6 & 7.5 \\
\hline$Q_{2}(\mathrm{MPa})$ & -104 & -80 & -68 & -40 & -15 & -13 & -8.4 & -4.5 \\
\hline
\end{tabular}

Table 2: Model parameters for type I specimen

\begin{tabular}{|c|c|c|c|c|c|c|c|}
\hline & $20^{\circ} \mathrm{C}$ & $300^{\circ} \mathrm{C}$ & $500^{\circ} \mathrm{C}$ & $600^{\circ} \mathrm{C}$ & $700^{\circ} \mathrm{C}$ & $800^{\circ} \mathrm{C}$ & $900^{\circ} \mathrm{C}$ \\
\hline$E(\mathrm{GPa})$ & 194 & 153 & 141 & 123 & 105 & 79 & 62 \\
\hline$R_{0}(\mathrm{MPa})$ & 170 & 148 & 112 & 77.4 & 13 & 2 & 2 \\
\hline$K(\mathrm{MPa})$ & 81.5 & 92 & 100 & 117 & 144 & 110 & 71.5 \\
\hline$n$ & 24.2 & 24 & 18.8 & 13.9 & 7.5 & 5.7 & 5.4 \\
\hline$C_{1}(\mathrm{MPa})$ & 163860 & 104070 & 89990 & 84790 & 36790 & 13850 & 4935 \\
\hline$D_{1}$ & 2000 & 2000 & 2000 & 2000 & 2000 & 2000 & 2000 \\
\hline$C_{2}(\mathrm{MPa})$ & 32500 & 12855 & 11925 & 9770 & 3335 & 470 & 240 \\
\hline$D_{2}$ & 200 & 200 & 200 & 200 & 200 & 200 & 200 \\
\hline
\end{tabular}

Table 3: Model parameters for type II specimen 


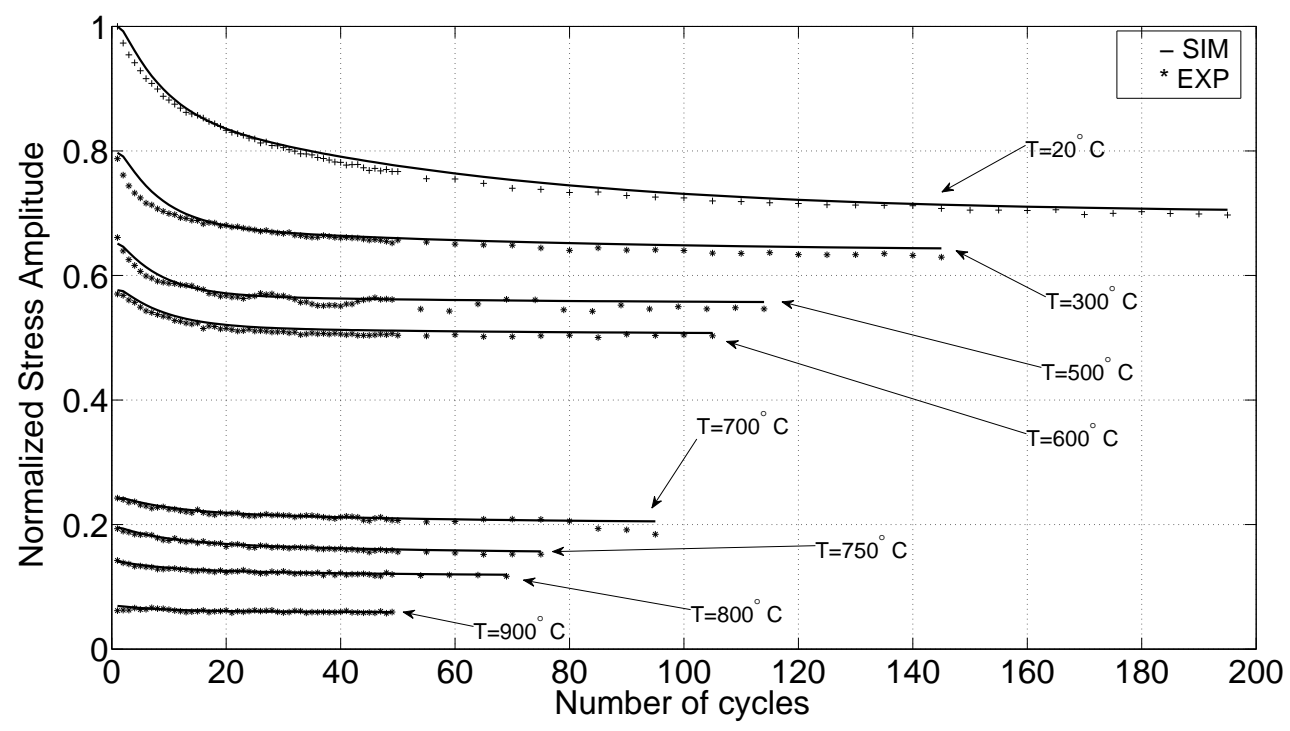

Figure 8: Comparison sim./exp. of stress amplitude versus cumulative plastic strain (type I specimen)

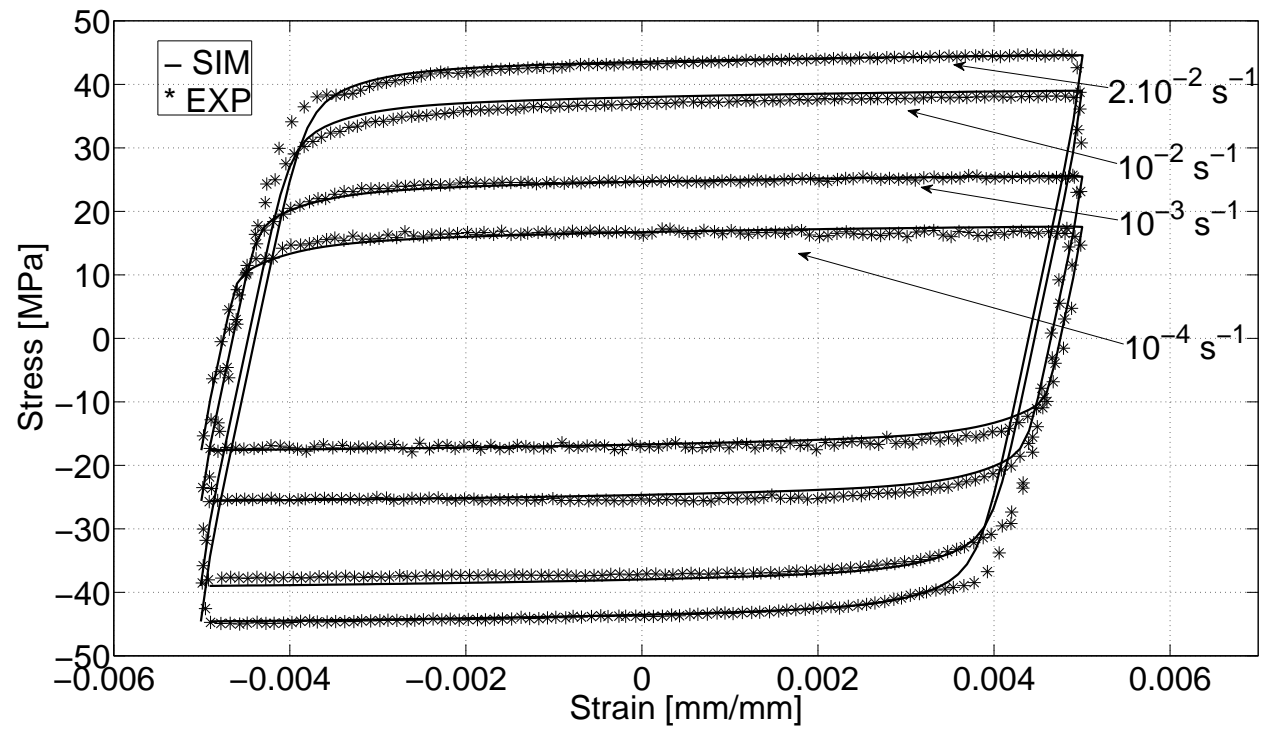

Figure 9: Comparison sim./exp. of stress-strain response at $900^{\circ} \mathrm{C}$ and three strain rates of $10^{-2} s^{-1}, 10^{-3} s^{-1}$ and $10^{-4} s^{-1}$ (type I specimen) 


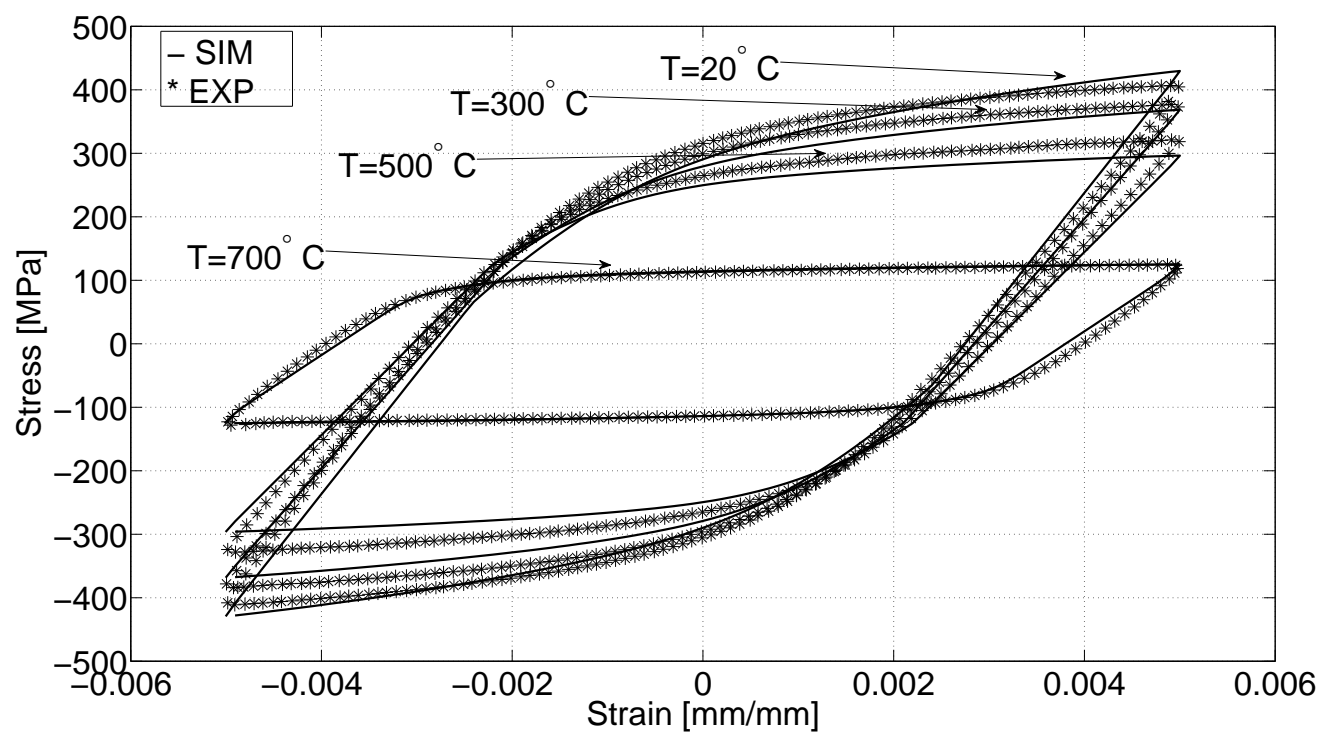

Figure 10: Comparison Sim./Exp. of Stress-Strain response at a strain rate of $10^{-2} s^{-1}$ and four temperature levels (type I specimen)

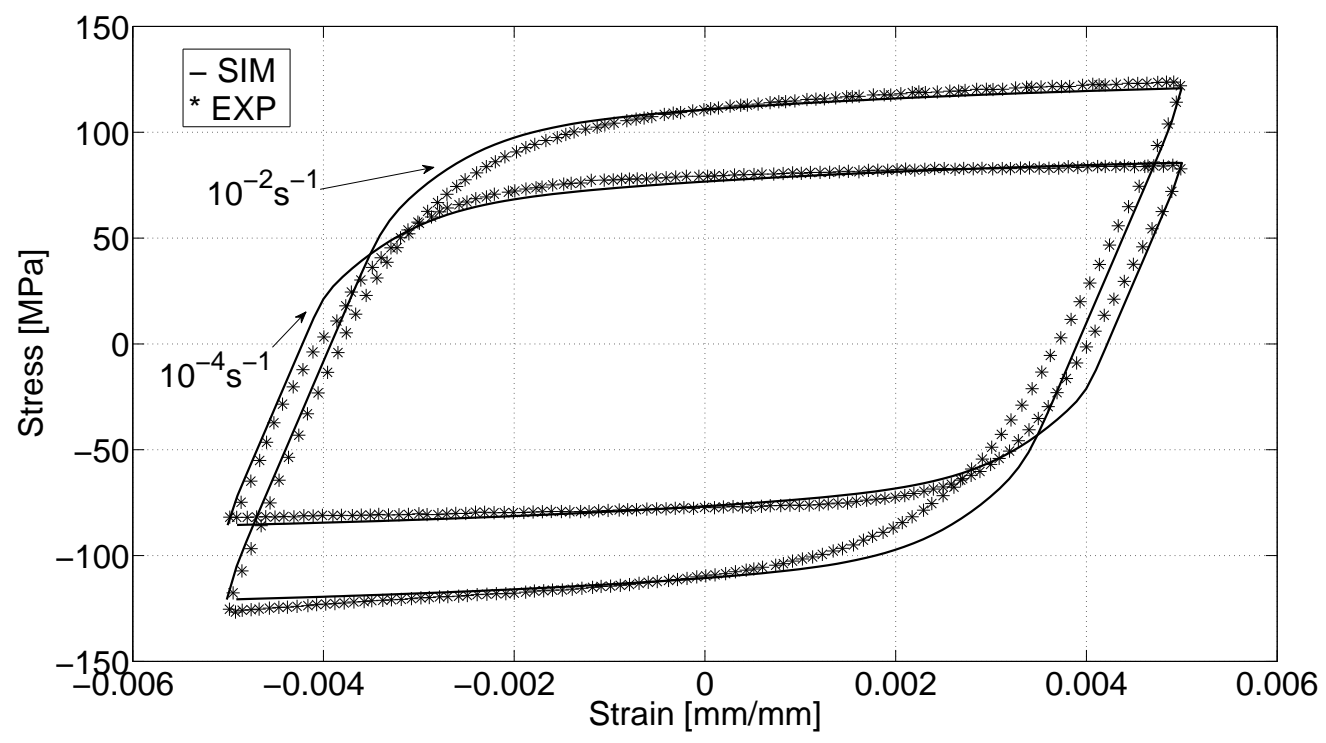

Figure 11: Comparison sim./exp. of stress-strain response at $700^{\circ} \mathrm{C}$ and two strain rates of $10^{-2} s^{-1}$ and $10^{-4} s^{-1}$ (type II specimen) 


\begin{tabular}{|c|c|c|c|c|c|c|c|c|}
\hline \multirow{2}{*}{ Specimen } & \multirow{2}{*}{$\begin{array}{l}\Delta T \\
\left({ }^{\circ} C\right)\end{array}$} & \multirow{2}{*}{$\Delta \varepsilon(\%)$} & \multicolumn{4}{|c|}{ loading sequence } & \multirow{2}{*}{$\dot{\varepsilon}\left(s^{-1}\right)$} & \multirow{2}{*}{$\dot{T}\left({ }^{\circ} C^{-1}\right)$} \\
\hline & & & $\mathrm{IP}$ & $\mathrm{OP}$ & $\mathrm{OPC}$ & OPT & & \\
\hline Anb1 & $200 / 400$ & 0.6 & 1 & - & 2 & - & $7.510^{-5}$ & 2.5 \\
\hline Anb2 & $200 / 400$ & 0.6 & - & 1 & - & 2 & $7.510^{-5}$ & 2.5 \\
\hline Anb3 & $300 / 500$ & 0.6 & 1 & - & 2 & - & $7.510^{-5}$ & 2.5 \\
\hline Anb4 & $300 / 500$ & 0.6 & - & 1 & - & 2 & $7.510^{-5}$ & 2.5 \\
\hline Anb5 & $300 / 500$ & 0.8 & 1 & 2 & 3 & - & $8.010^{-5}$ & 2.0 \\
\hline AnH6 & $500 / 700$ & 0.65 & 1 & - & 2 & - & $7.510^{-5}$ & 2.5 \\
\hline AnH7 & $500 / 700$ & 0.65 & - & 1 & - & 2 & $7.510^{-5}$ & 2.5 \\
\hline $\mathrm{AnH} 8$ & $650 / 850$ & 0.6 & 1 & - & 2 & - & $7.510^{-5}$ & 2.5 \\
\hline AnH9 & $650 / 850$ & 0.6 & - & 1 & - & 2 & $7.510^{-5}$ & 2.5 \\
\hline AnH10 & $700 / 900$ & 1.0 & 1 & 2 & 3 & - & $1.010^{-4}$ & 2.0 \\
\hline
\end{tabular}

Table 4: Anisothermal test schedule

\subsection{Prediction capability assessment for complex loadings}

The car component under study is subjected to complex thermo-mechanical loadings, including fast temperature increase/decrease, and long holding time at high and low temperatures. The models identified in isothermal conditions should then be able to predict the mechanical responses of the material under loadings more representative of real in-service loadings than LCF cycles.

\subsubsection{Anisothermal loadings}

Four types of TMF tests were performed: In-Phase (IP) test (maximum strain occurs at maximum temperature), Out-Of-Phase (OP) test (maximum strain occurs at minimum temperature), Out-of-Phase-Compression (OPC) test (maximum strain occurs at minimum temperature and with only compressive mechanical strain), and Out-of-Phase-Tensile (OPT) test (maximum strain occurs at minimum temperature and with only tensile mechanical strain). For each test, before any load was applied, ten thermal cycles were performed in order to achieve thermal dynamic stabilisation.

Each specimen was subjected to two types of loading: IP followed by OPC, or OP followed by OPT. The test plan is given in Table 4 .

The coefficients of the base metal model were linearly interpolated from the identified values at the tested temperatures. Predicted material response and real response for $\mathrm{OPT} 300-500^{\circ} \mathrm{C}$ are compared in Figure 12. It can be seen that the experimental and predicted results are in good agreement in this temperature range. 


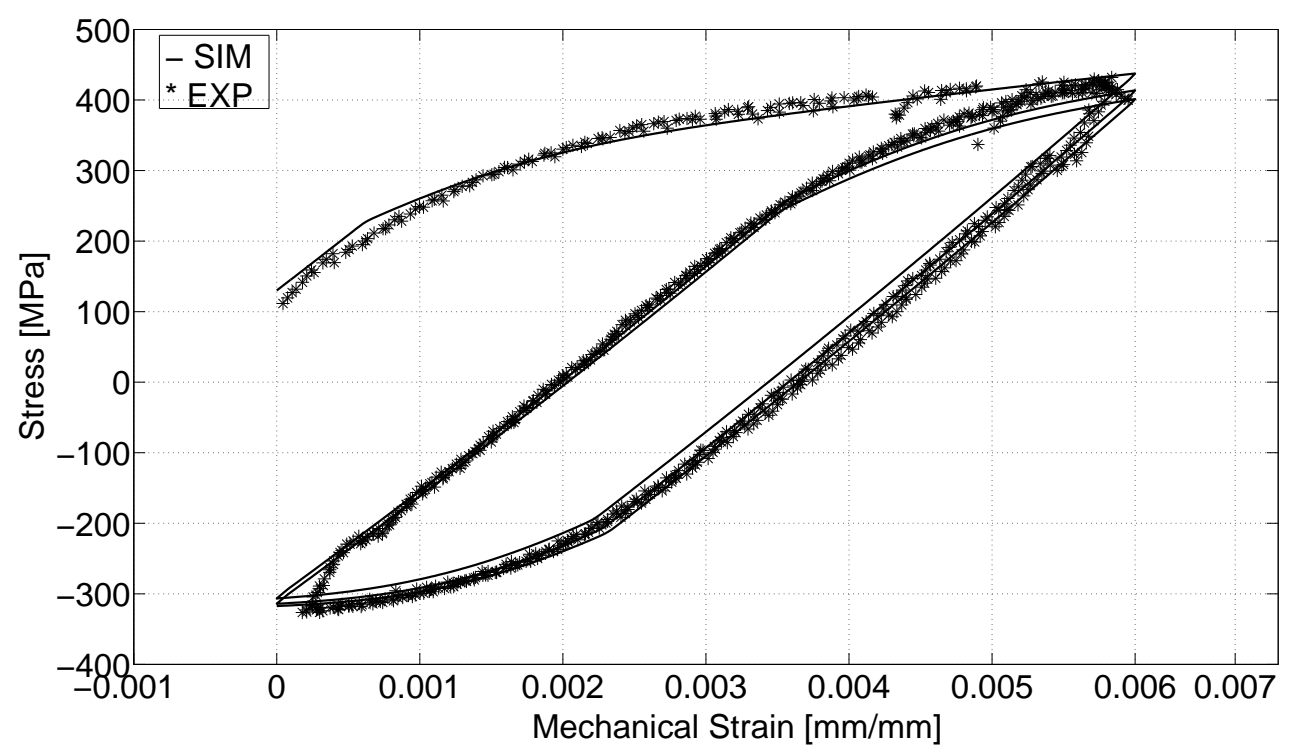

Figure 12: Comparison sim./exp. of stress-strain response for an OPT test at $300-500^{\circ} \mathrm{C}$

When simulating anisothermal tests at higher temperatures $\left(T_{\max }\right.$ greater than $600^{\circ} \mathrm{C}$ ), the model overestimates the stress amplitude. From isothermal tests, it is known that the higher the test temperature, the faster stress stabilisation is reached. In other words, softening is not only mechanically but also thermally activated. To take into account the sole effect of temperature, the base metal cyclic behaviour was described using the identified model but modifying the value of the isotropic hardening variable. Indeed, $R$ was therefore set at its asymptotic value. Comparison of the experimental and numerical results for IP $500-700^{\circ} \mathrm{C}$ is given in Figure 13 . Correlation is good, although the rate of stabilisation due to the thermal effect was not evaluated here.

\subsubsection{Isothermal loading with dwell time}

Under thermal loading, an industrial component mainly expands or contracts elastically. Only some small zones escape free thermal strain and undergo plastic deformation. These zones are small enough to consider that the whole structure imposes the loading on them. When a component is subjected to long holding time at high or low temperatures, the plastic zones are then subjected to a long dwell time. 


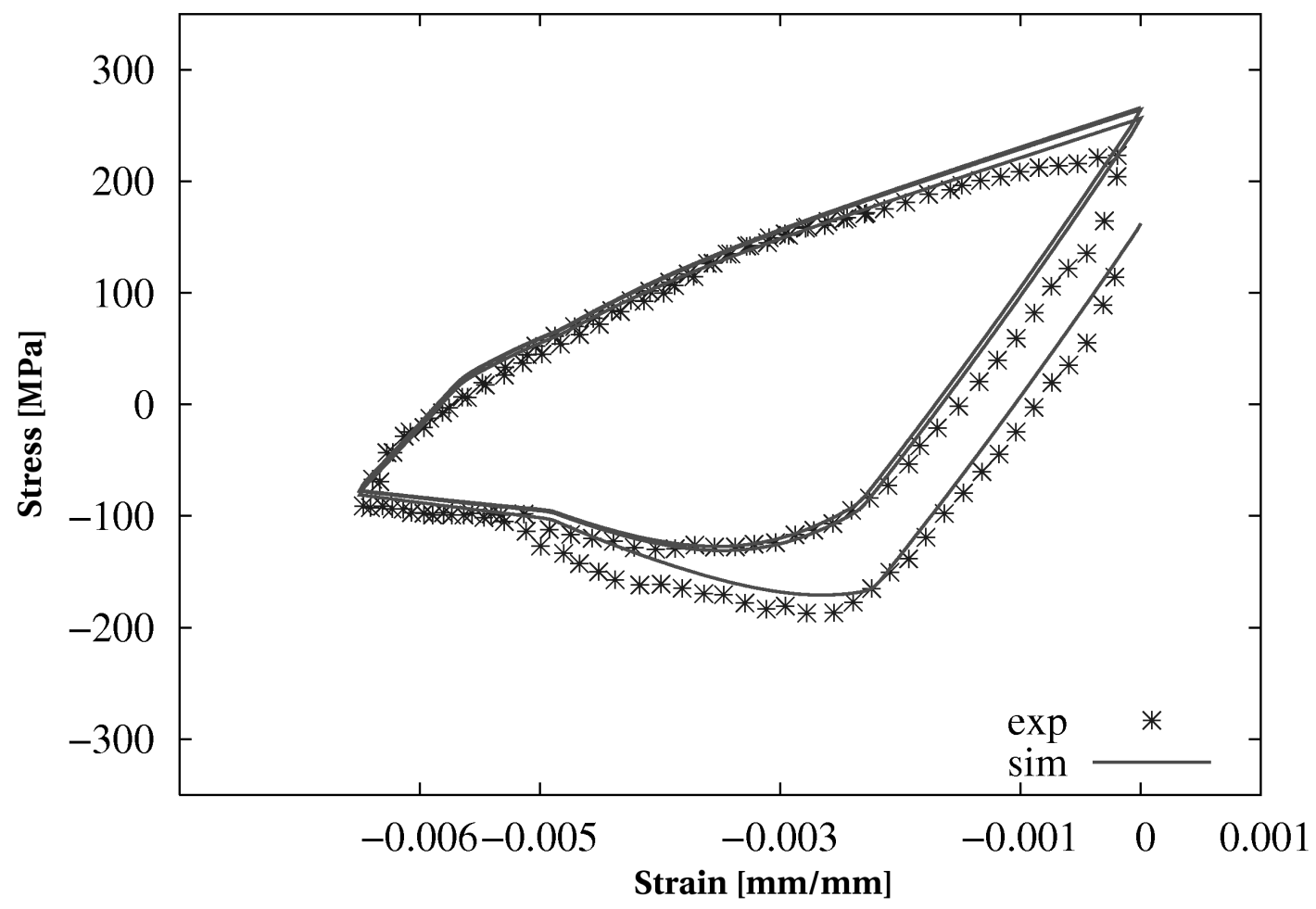

Figure 13: Comparison sim./exp. of stress-strain response for an $\mathrm{OPC}$ test at $500-700^{\circ} \mathrm{C}$ 
Consequently, isothermal tests including dwell time were performed on base metal specimens to validate model reliability in predicting mechanical response to such conditions at high temperature. Figure 14 shows that the numerical predictions are in good agreement with experimental results. Thus, the viscous constitutive parameters identified from the stabilised cycle at different strain rates are relevant in reproducing stress relaxation occurring at high temperature during dwell time.

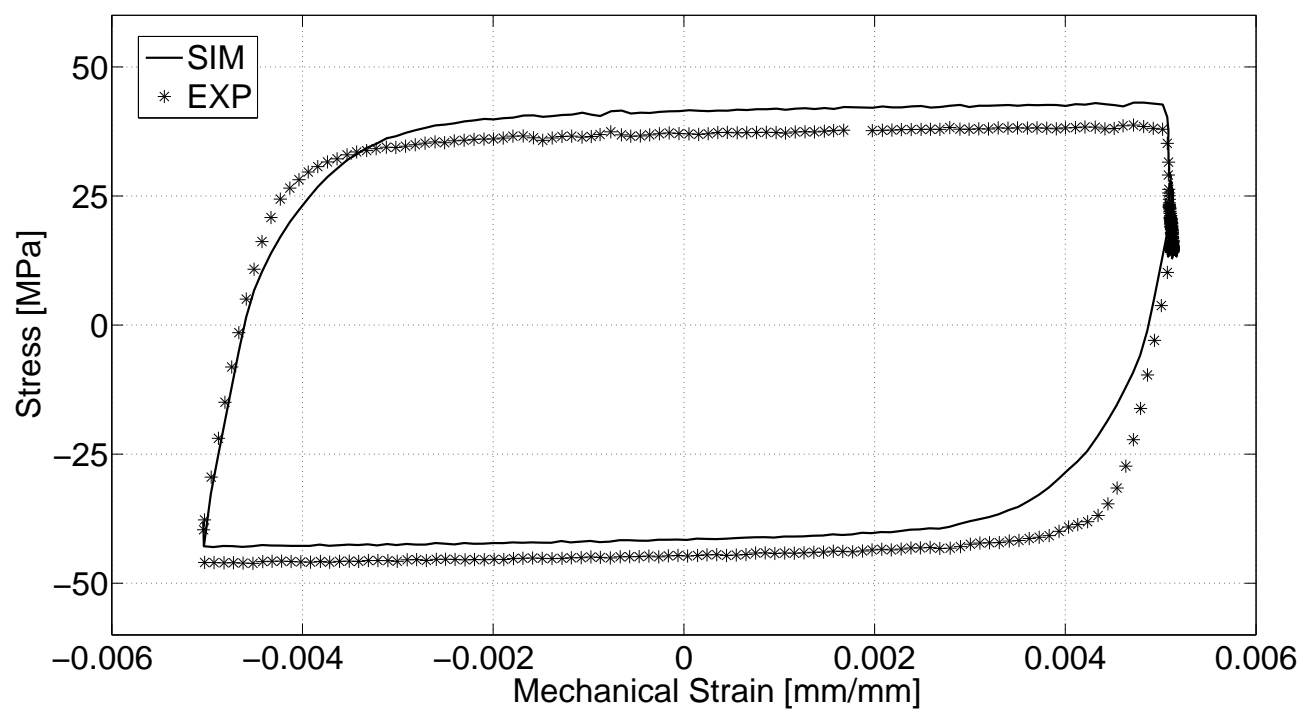

Figure 14: Comparison sim./exp. of stress-strain response for an isothermal test at $800^{\circ} \mathrm{C}$ with 30 s dwell time

\section{Study of the response of a bi-material specimens under push-pull tests}

In order to get better insight into the bi-material effect on strain distribution in welded zones, two cyclic tests were performed on welded specimens. In this section, the test configuration concerned only specimens with a welded zone of only $2 \mathrm{~mm}$ in length for which an extensometer gauge length of $12 \mathrm{~mm}$ was used. The Area Of Interest (AOI) considered for DIC measurement is $8 \times 17 \mathrm{~mm}^{2}$ (see Fig. 15). Thus, the mechanical response of the bi-material tensile-compressive loadings could be investigated and discussed.

Experimental results were then compared to numerical results to evaluate the accuracy of the identified models and define the best modelling conditions. Next, the bi-material effect on stress distribution was numerically studied. 


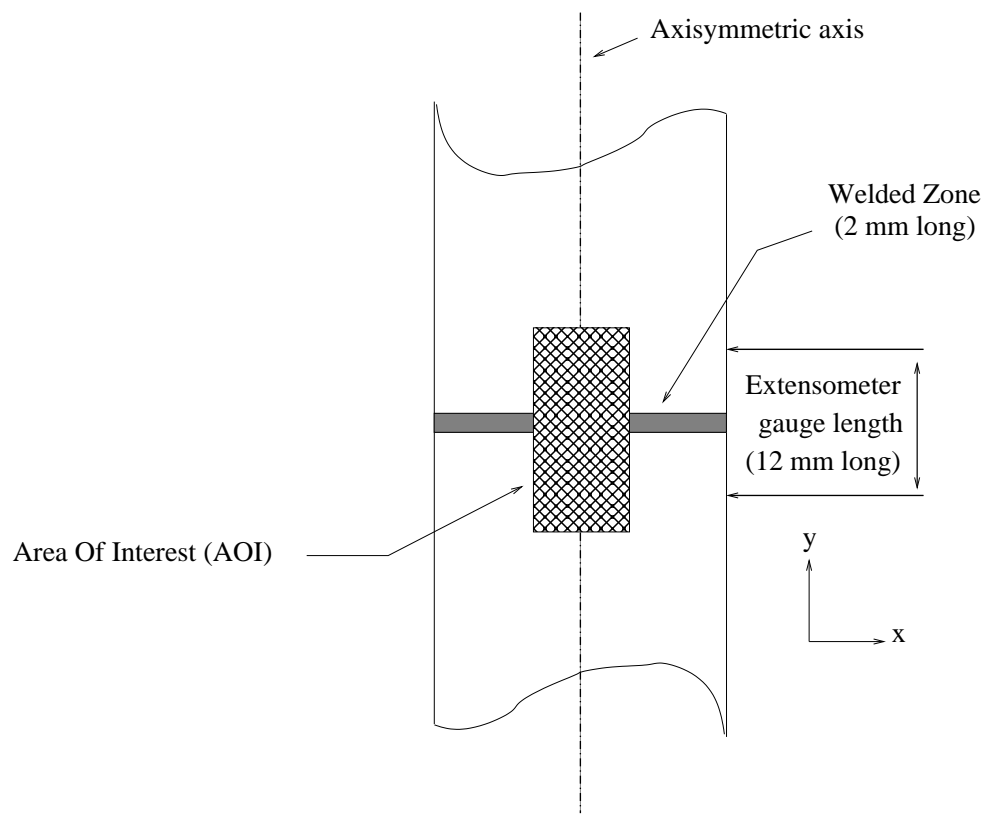

Figure 15: Tubular bi-material specimen with $2 \mathrm{~mm}$ thickness

\subsection{Experimental procedure}

Each time it was recorded, the 3D specimen shape was reconstructed and displacements were computed by local optimisation of a correlation function. Accuracy depends on the camera's configuration (resolution, angle between cameras, etc.) and on the number of grey levels in the local zone. The magnification factor considered is 25 pixels $/ \mathrm{mm}$, the square subset size which defines the displacement spatial resolution was chosen equal to 19 pixels, corresponding to a resulting resolution of $0.76 \mathrm{~mm}$. The accuracy of the DIC technique in assessing 3D displacement fields is discussed in different works [25, 26, 20]. For instance, it consists in performing a no-motion experiment to evaluate errors from image noise or a no-strain experiment to assess errors from rigid body motions [30]. The 2D strain tensor was computed by numerical derivation from the displacements at several points around the point of interest. Indeed, it was computed using the displacement function derived from a set of neighbouring matched points chosen in a square surface. In the present work, a specific test procedure was set up for monitoring the evolution of strain distribution during a tension compression test (see Fig. 16):

- specimen setting and recording of an initial pair of images to be considered as 
a reference for strain computation,

- checking extensometer positioning by Young's modulus measurement and returning to zero force, and

- test launching. Every ten cycles, strain distribution was monitored. At the beginning of each recorded cycle, cameras and the testing machine were manually synchronised. To facilitate this stage, the strain rate was lowered $\left(\dot{\varepsilon}=1 \cdot 25 \cdot 10^{-4} s^{-1}\right)$. Then a pair of images was taken every $2 \mathrm{~s}$ which allowed accurate strain evolutions to be measured whereas a higher strain rate of $4.10^{-3} s^{-1}$ was considered for the intermediate cycles.

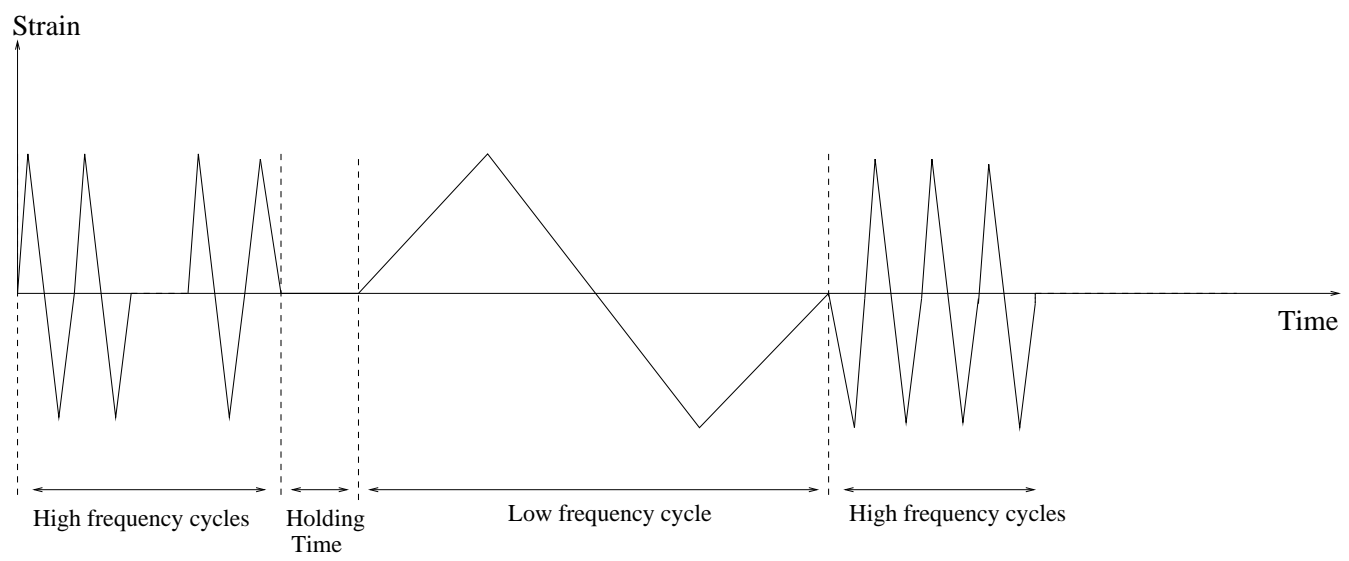

Figure 16: Test procedure

\subsection{Experimental results of the DIC measurements}

Before computing any field, it is necessary to establish correspondences between pairs of images. However, during the first loading (Young's modulus measurement), a rigid body motion appeared due to the set up of the sample into the jaws of the test machine. It was then meaningless to compute strains from the initial pair of images. In the following, all strains at time $t$ were computed from displacements between pairs of images at time $t$ and pairs of images at time zero of the $10^{\text {th }}$ cycle (reference).

Once strain computation was achieved, we compared the average strain (obtained by digital image correlation technique) in extensometer gauge to the strain measured 
by extensometer. Figure 17 reveals that the agreement between the two measurements is excellent at the $10^{\text {th }}$ cycle. Agreement between the two measurements at the $80^{\text {th }}$ cycle, however, is not so good. At the $10^{\text {th }}$ cycle, the DIC measurements have exhibited axial strain field perpendicular to the loading axis. At the $80^{\text {th }}$ cycle, a deviation of the axial strain field was observed. This phenomenon could be explained by different assumptions. Indeed, it could be due to a slight misalignment of the testing machine, a coaxiality default of the sample or a welding asymmetry. However, at that time, it was not possible to further investigate the effect of each parameter on the deviation.
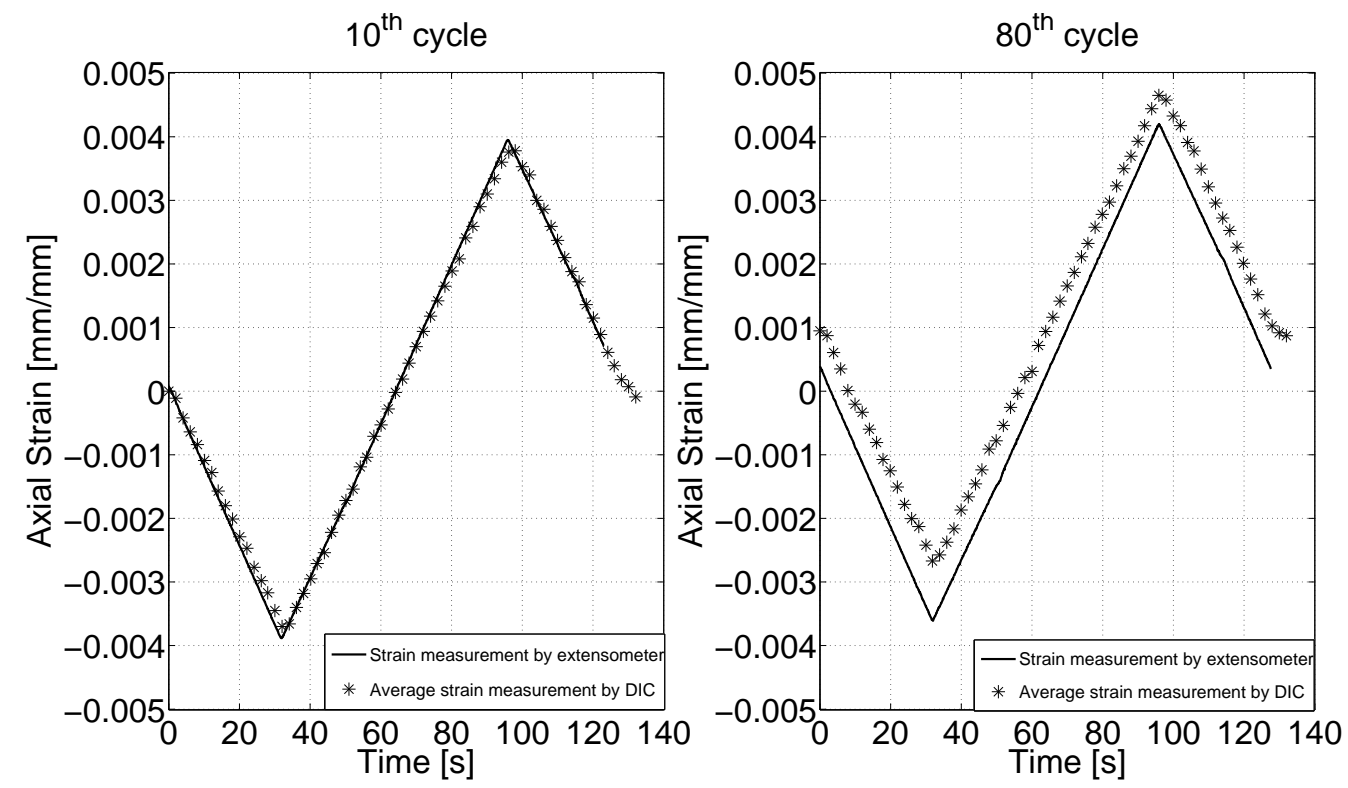

Figure 17: Strain measurements obtained by extensometer and digital image correlation technique at the $10^{\text {th }}$ and $80^{\text {th }}$ cycle

Axial strain distribution along a line parallel to the tube axis was also investigated (see Fig. 18). Results are given for the $10^{\text {th }}$ and $30^{\text {th }}$ cycles. Strain distribution was measured at several macroscopic strain levels, indicated in Figure 19. Table 5 sums up all strain levels studied. Figures 20 and 21 illustrate axial strain profiles. Strain gradients are steeper at the $10^{\text {th }}$ cycle compared to the $30^{\text {th }}$ cycle. Looking at the strain profile evolution it can been observed that:

- The B profile is roughly a translation of the A profile, which corresponds to elastic shakedown. 
- The C profile is significantly different from the B profile. As load increases, strain concentrates in the welded metal and HAZ. The same conclusion can be made comparing the $\mathrm{D}$ and $\mathrm{C}$ profiles.

- The E and F profiles are roughly translations of the D profile. Again, simple elastic shakedown occurs in this part of the cycle.

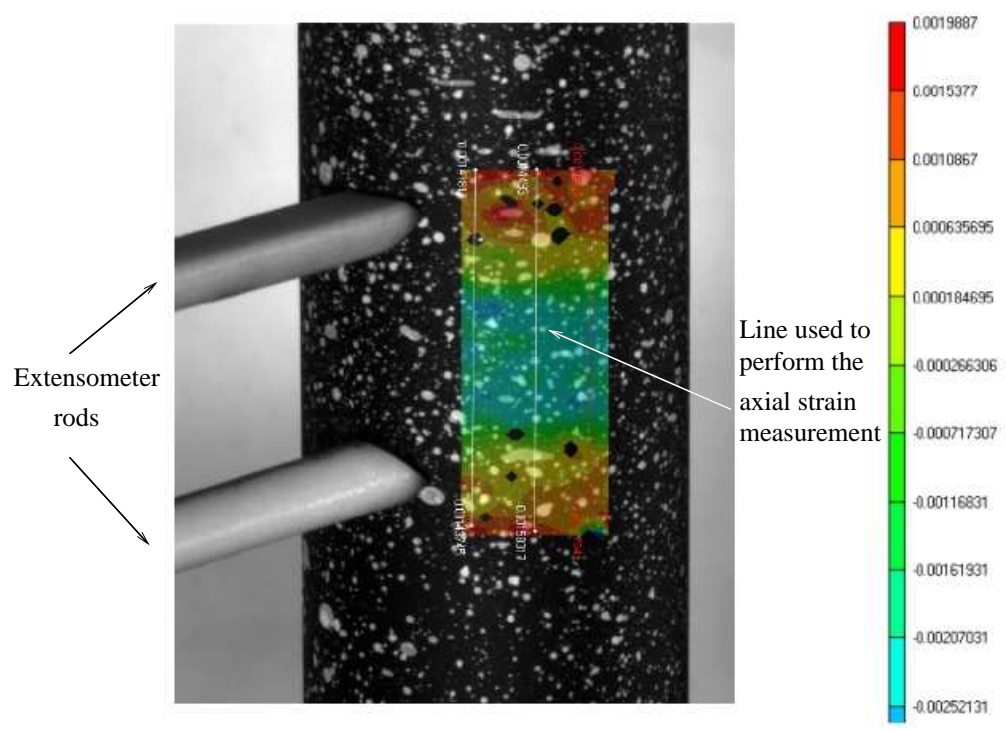

Figure 18: Axial strain field obtained at the $10^{\text {th }}$ cycle (and a time of $t=55 \mathrm{~s}$ ) by DIC technique along one line parallel to the tube axis

\begin{tabular}{|c|c|c|c|c|c|c|c|}
\hline \multicolumn{2}{|c|}{} & \multicolumn{6}{|c|}{ Different moments in the cycle } \\
\cline { 3 - 8 } \multicolumn{2}{|c|}{} & $\mathrm{A}$ & $\mathrm{B}$ & $\mathrm{C}$ & $\mathrm{D}$ & $\mathrm{E}$ & $\mathrm{F}$ \\
\hline \multirow{2}{*}{ Average strain (\%) } & $10^{\text {th }}$ cycle & -0.37 & -0.13 & 0.24 & 0.38 & - & 0.12 \\
\cline { 3 - 9 } & $30^{\text {th }}$ cycle & -0.319 & -0.116 & 0.211 & 0.344 & 0.32 & 0.155 \\
\hline
\end{tabular}

Table 5: Strain distribution obtained within the $10^{\text {th }}$ and $30^{\text {th }}$ cycles

\subsection{Test simulation}

The test simulation of the tension compression test on the bi-material specimen was performed using the finite element code ABAQUS ${ }^{T M}$. The finite element simulation of the elasto-viscoplastic problem consists in:

- solving the equilibrium system $\underline{K} \vec{u}=\vec{F}$, with $\underline{K}$ the global stiffness matrix, $\vec{u}$ the node displacements and $\vec{F}$ the external loads. 


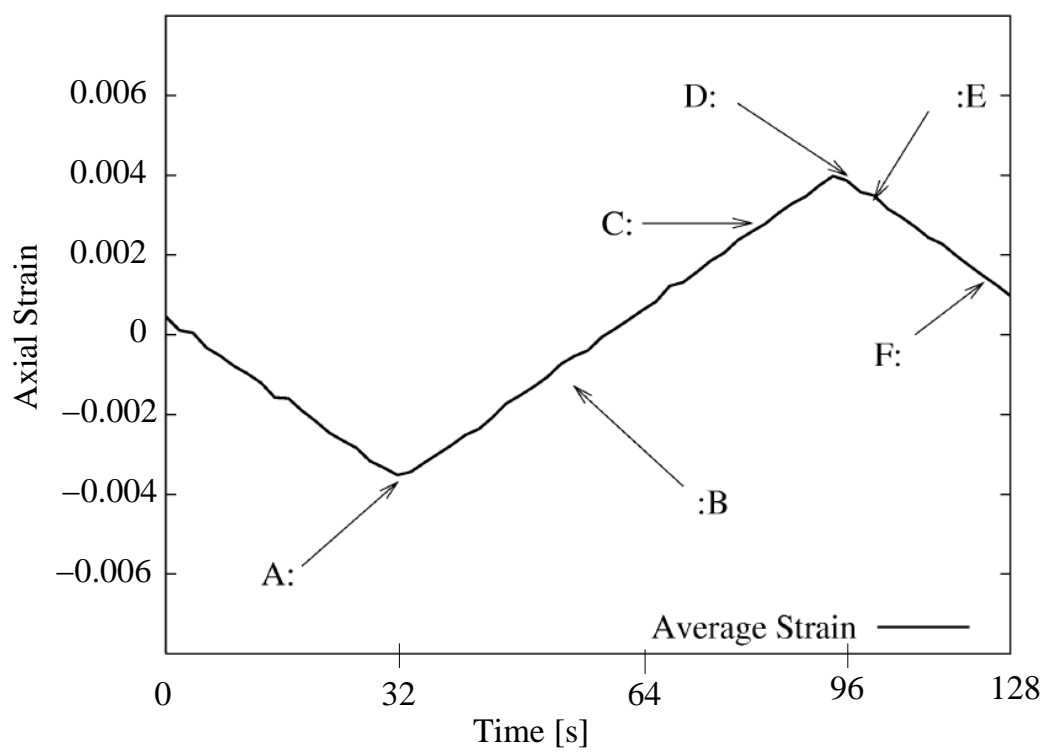

Figure 19: Considered points of the analysed cycle

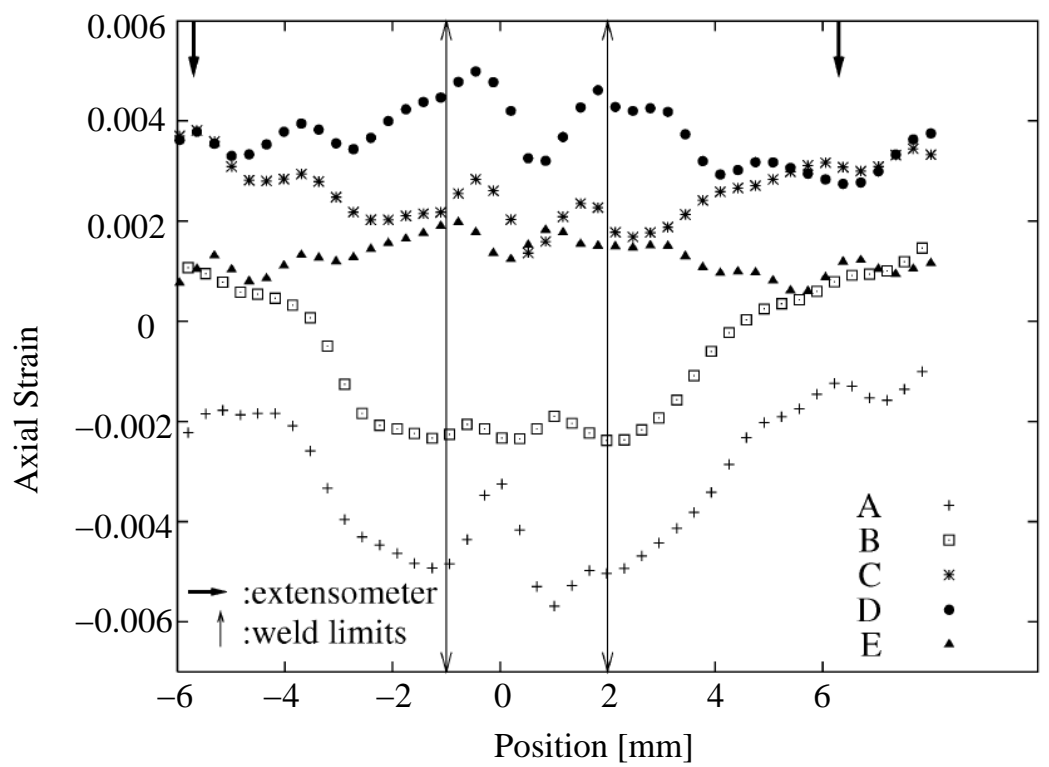

Figure 20: Strain profile at the $10^{\text {th }}$ cycle 


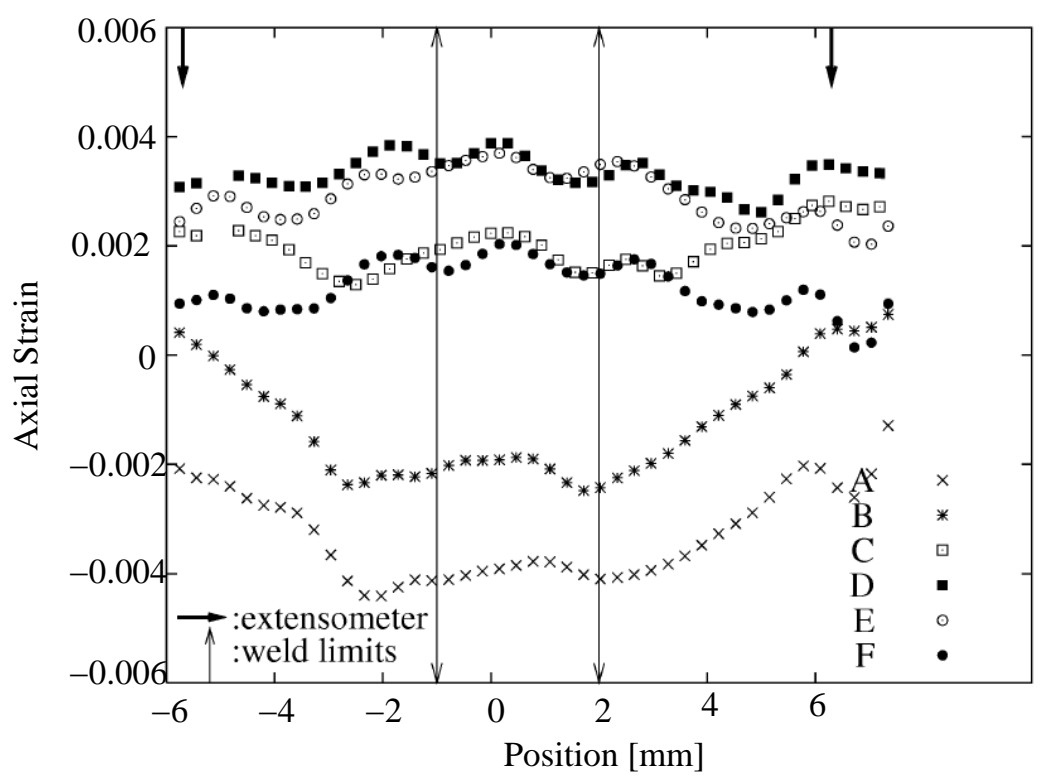

Figure 21: Strain profile at the $30^{\text {th }}$ cycle

- performing the local integration of the behaviour model equations within each element.

In order to solve the local equations (behaviour model), an implicit integration method was implemented in a UMAT user subroutine.

From the experimental results and based on metallurgical observations, it is recommended that the cyclic test be simulated with a 3-zone model (Fig. 22): base metal, HAZ and melted metal. To take into account recovery in HAZ, only the yield stress was modified compared to the base metal model. Two different hypotheses were put forward: either recovery is considered complete in all HAZs, or recovery is partial and depends on the distance to the welded metal (yield stress gradient is introduced). The first approach considers a complete recovery model which means that the HAZ behaviour was defined as the stabilised behaviour of the base metal. In this case, a constant isotropic component was considered, equals to the yield stress of the stabilised behaviour of the base metal. In the second approach, a partially recovery model was considered and an evolution of the isotropic hardening was assumed. Dimensions of the three zones were determined according to metallurgical observations.

The area shapes I, II and III are illustrated in Figure 22. 


\begin{tabular}{|c|c|c|c|c|c|c|}
\hline & \multicolumn{3}{|c|}{ Model } & \multicolumn{2}{c|}{ Mesh } & Boundary conditions \\
\cline { 2 - 6 } & I: Base metal & II: HAZ & III: Welded metal & Type & Element Number & \\
\hline Model 1 & BM & BM & WM & Axisymetric & 386 & Displacement \\
Model 2 & BM & recov. BM & WM & Axisymetric & 386 & Displacement \\
Model 3 & BM & partially recov. BM & WM & Axisymetric & 386 & Displacement \\
\hline
\end{tabular}

Table 6: Numerical plan

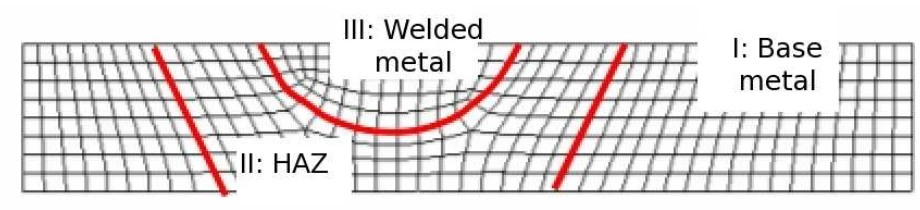

Figure 22: Meshing and areas considered for the finite element simulation cases

Simulation conditions with three different models are shown in Table 6. The BM, WM, recov. BM and partially recov. BM models are respectively the base metal model, the welded metal model, the base metal model with a complete recovery and the base metal model with a partially recovery. The first model is the simplest one since specific HAZ behaviour is not taken into account and is expected to be less accurate than the two others.

The comparison between experimental and simulated data was performed for the $30^{\text {th }}$ cycle. All models provided meaningful results (see Fig. 23 to Fig. 25). Nevertheless, as expected, profile tendency was better reproduced by models 2 and 3. On the $\mathrm{C}$ profile especially, strain minima in HAZ is only predicted by these models.

The model accuracy was defined by computing the error in average strain in the melted metal. Except for low strain levels (profiles B and F), error was less than $10 \%$. Higher error at lower strain level could be attributed to reduced accuracy of identified models in the elastic plastic transition (models were identified at 1\% strain 


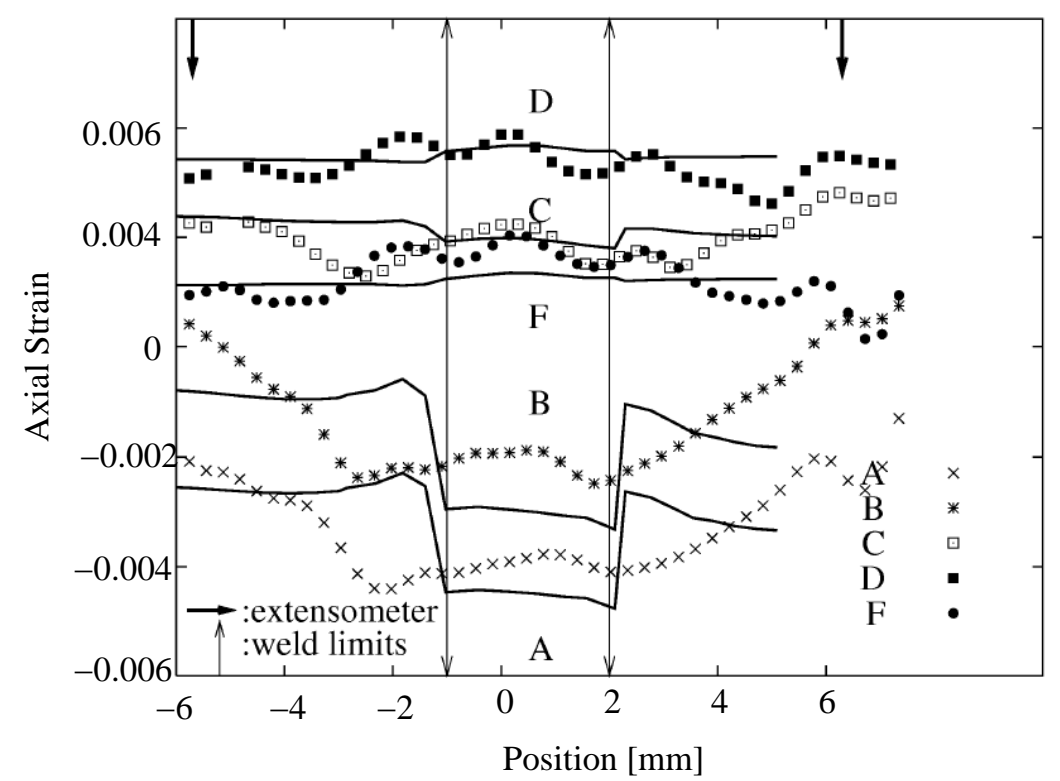

Figure 23: Comparison between measured and simulated strain profiles for model 1 (line: simulation; data points: experimental values from DIC)

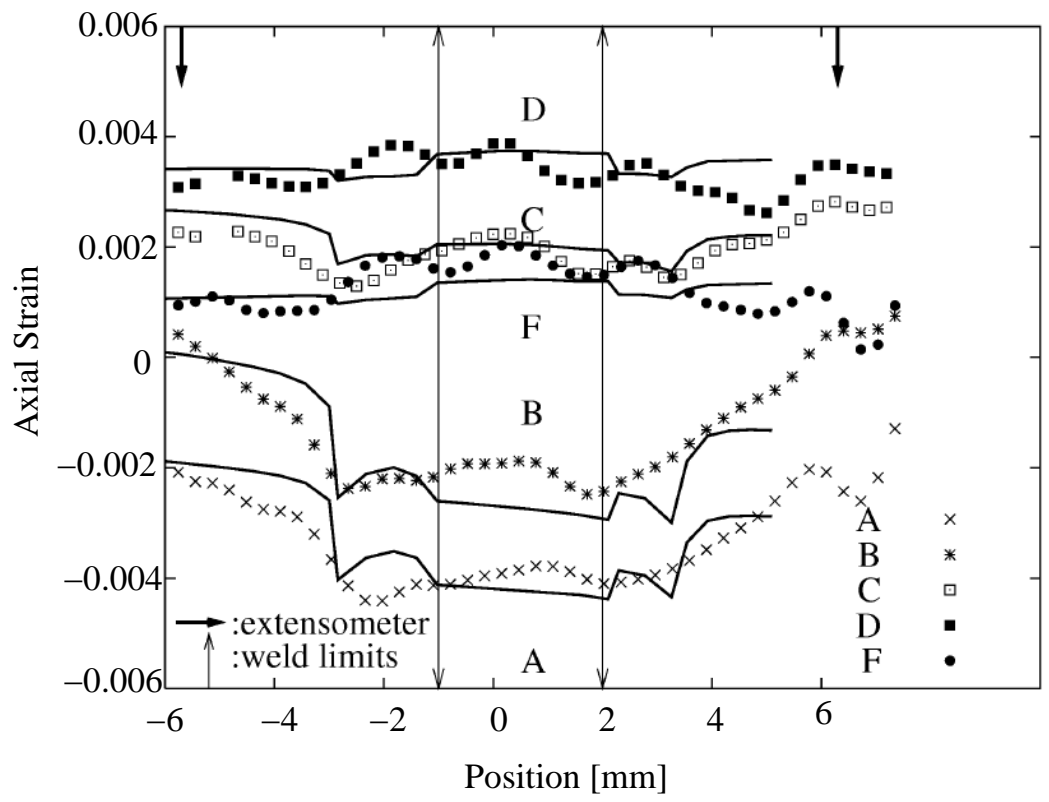

Figure 24: Comparison between measured and simulated strain profiles for model 2 (line: simulation; data points: experimental values from DIC) 


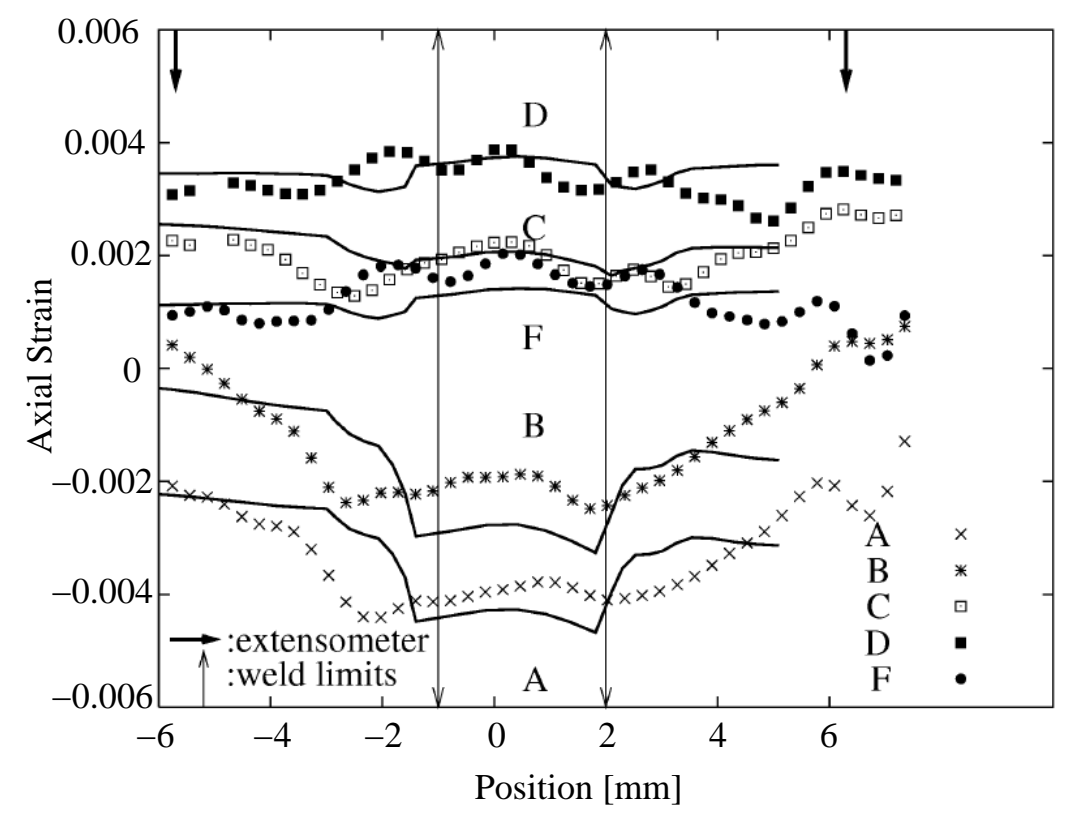

Figure 25: Comparison between measured and simulated strain profiles for model 3 (line: simulation; data points: experimental values from DIC)

level).

\section{Conclusion}

An innovative experimental method was set up to characterise the local behaviour of the welded zones of a tubular component. Particular attention was paid to the design of base and melted metal specimens, in order for their microstructure to be as close as possible to that found in a real welded component. These specimens were submitted to cyclic isothermal and anisothermal tension compression tests. Elasto-viscoplastic constitutive model parameters were identified for welded and base metals from isothermal tests. The model takes into account kinematic hardening, strain rate and isotropic hardening. It was found relevant to describe the results of anisothermal tests. In order to get better insight into the mechanical response of a welded zone, strain field was measured by digital image correlation technique during a tension compression test on a welded specimen at room temperature. This technique allowed the evolution of strain distribution while cycling to be followed and the three-zone FEM model of welded zones to be validated. Different models based on microstructural observations and hardness measurements were identified 
to take into account the HAZ's behaviour. They have shown a significant impact on the local strain amplitude and stress triaxiality levels, and hence on the expected fatigue lifetime in low cycle fatigue regime. The different models considered to take into account the HAZ's behaviour have shown a significant impact on the local strain amplitude and stress triaxiality levels, and hence on the expected fatigue lifetime in low cycle fatigue regime. Stress triaxialility factor is given as the ratio of the hydrostatic stress $\sigma_{H}$ to the equivalent von Mises stress $\sigma_{e q}, \frac{\sigma_{H}}{\sigma_{e q}}$, with the following formulations:

$$
\sigma_{H}=\frac{1}{3}\left(\sigma_{1}+\sigma_{2}+\sigma_{3}\right) ; \quad \sigma_{e q}=\frac{1}{\sqrt{2}} \sqrt{\left(\sigma_{1}-\sigma_{2}\right)^{2}+\left(\sigma_{1}-\sigma_{3}\right)^{2}+\left(\sigma_{2}-\sigma_{3}\right)^{2}}
$$

where $\sigma_{1}, \sigma_{2}, \sigma_{3}$ are the first, second and third major stresses.

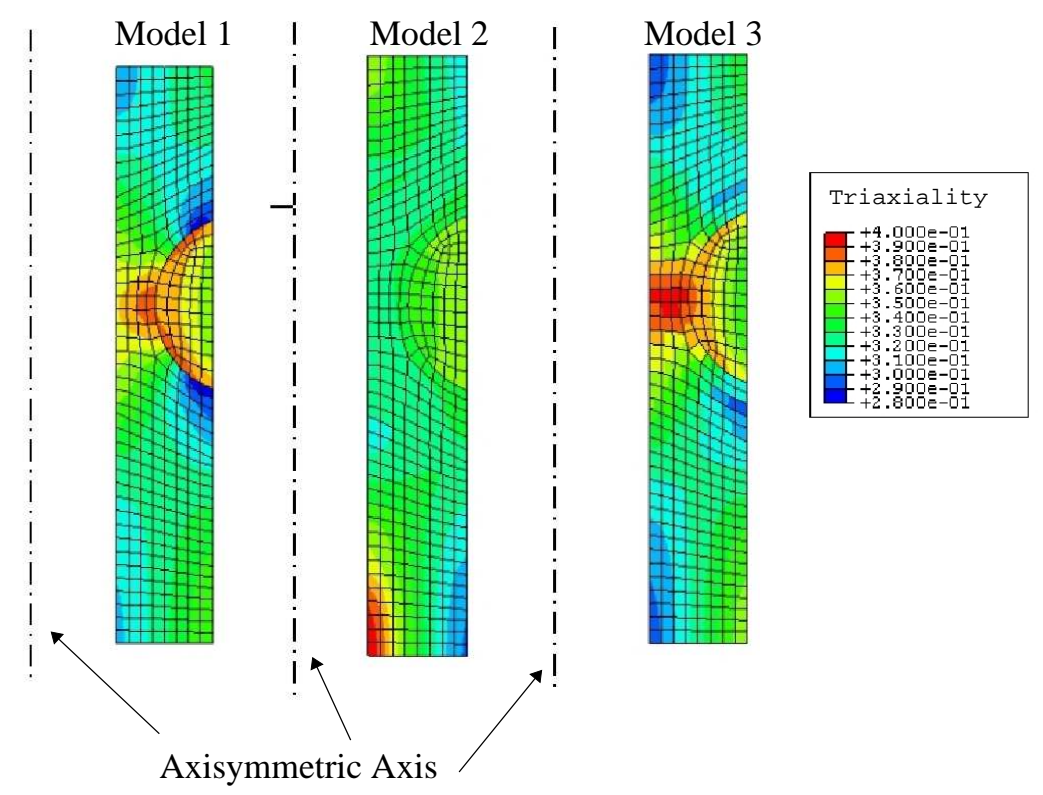

Figure 26: Calculated stress triaxility distribution at maximum strain level of the $80^{\text {th }}$ cycle as a function of the model's assumption

The three proposed simulations were performed up to the $80^{\text {th }}$ cycle. At that time, the behaviour of the structure was almost stabilised. It was possible to analyse the impact of the different model hypotheses on this pseudo stabilised behaviour. The strain amplitude predicted in welded metal was equivalent in the three simulations. Strain amplitude predicted in base metal and HAZ strongly depends on the model. Model 1 underestimates by $10 \%$ the maximum strain amplitude in these zones. A distinction between models 2 and 3 can be made considering the significant 
impact on stress triaxility distribution (see Fig. 26). Both strain distribution and stress triaxiality have a strong impact on the low cycle fatigue lifetime and in particular on thermal fatigue $([31][32],[33],[34])$. From the analysis of fatigue lifetime of these types of specimens, it should then be possible to decide on the most relevant model. This will be the subject of future work.

\section{Acknowledgements}

The authors would like to express their sincere thanks to Laurent Robert for the fruitful discussions related to the digital image correlation technique and the use of Vic-3D software. They also acknowledge Andy Meehan for his help in the proofreading of this article.

\section{References}

[1] M. Okazaki and Y. Mutoh. Low cycle fatigue strength and its prediction for dissimilar metal electron beam welded joints at high temperature. High Temperature Creep Fatigue, 3, 1988.

[2] Y. Madi, P. Matheron, N. Racho, and P. Mongabure. Low cycle fatigue of welded joints: new experimental approach. Nuclear Engineering and Design, 2004.

[3] M-C. Robin. Comportement et Dure de vie de pices Tubulaires, soudes ou non, en acier ferritique 1.4509: application automobile. $\mathrm{PhD}$ thesis, Mines ParisTech, 2010.

[4] J. Besson, Y. Madi, A. Mortarjemi, M. Koģak, G. Martin, and P. HorNET. Crack initiation and propagation close to the interface in a ferrite-austenite joint. Material Science Engineering A, 397, 2005.

[5] J. Lemaître and J.L Chaboche. Mechanics of Solid Materials. Cambridge University Press, 1990. 
[6] M. Takanashi, K. Kamataka, and I. Kunihiro. Relaxation behavior of welding residual stresses by fatigue loading in smooth longitudinal butt welded joints. Welding in the world, 44:28-34, 2000.

[7] C. Lachmann, Th. Nitschke-Pagel, and H. Wohlfahrt. Characterisation of residual stress relaxation in fatigue loaded welded joints by $x$ ray diffraction and barkhausen noise. In ECRS 5, Proceedings of the 5th European Conference on Residual Stresses, pages 374-379, 2000.

[8] S. Han, T. LeE, and B. Shin. Residual stress relaxation of welded steel components under cyclic load. Mater. Technol., 73:414-420, 2002.

[9] J.L Chaboche. Constitutive equations for cyclic plasticity and cyclic viscoplasticity. International Journal of Plasticity, 5:247-302, 1989.

[10] B. Halphen and Q. NGuyen. Plastic and viscoplastic materials with generalized potential. Mechanics research communication, 1:43-47, 1974.

[11] G. Cailletaud and K. Sai. Study of plastic viscoplastic models with various inelastic mechanisms. International Journal of Plasticity, 11:991-1005, 1995.

[12] S. Arnold and A. Saleeb. On the thermodynamic framework of generalized coupled thermoelastic-viscoplastic-damage modelling. International journal of plasticity, 10:263-278, 1994.

[13] A. Benallal and D. Marquis. Constitutive equations for non proportional cyclic elastoviscoplasticity. Journal of Engineering Materials and Technology, 109:326-336, 1987.

[14] N. Lautrou, D. Thevenet, and J.-Y. Cognard. Fatigue crack initiation life estimation in a steel welded joint by the use of a two-scale damage model. Fatigue and Fracture of Engineering Materials and Structures, 32:403-417, 2009.

[15] S. Panier, C. Robin, B. Wu, D. Zakrzewski, and G. Mesmacque. Experimental and numerical investigation of fatigue life of aluminium alloy welded components. In Fatigue Design, 2005. 
[16] F. Szmytka, L. RÉmy, H. Maitourtnam, A. Koster, and M. Bourgeois. New flow rules in elasto-viscoplastic constitutive models for spheroidal graphite cast iron. International Journal of Plasticity, 26:905-924, 2010.

[17] E. Charkaluk, A. Bignonnet, A. Constantinescu, and K. Dang Van. Fatigue design of structures under thermomechanical loadings. Fatigue and Fracture of Engineering Materials and Structures, 25:1199-1206, 2002.

[18] L. BuCHER. Etude de l'endommagement en fatigue thermique des aciers inoxydables F17TNb et R20-12 pour application automobile. PhD thesis, Mines ParisTech, 2004.

[19] D. Garcia, J.J Orteu, and L. Penazzi. A combined temporal tracking and stereo-correlation technique for accurate measurement of $3 \mathrm{D}$ displacements: application to sheet metal forming. Journal of Materials Processing Technology, 2002.

[20] L. Robert, V. Velay, N. Decultot, and S. Ramde. Identification of hardening parameters using finite element models and full-field measurements: some case studies. Journal of Strain Analysis, 47:3-17, 2011.

[21] V. GAFFARD. Experimental study and modelling of high temperature creep flow and damage behaviour of $9 \mathrm{Cr} 1 \mathrm{Mo}-\mathrm{NbV}$ steel weldments. PhD thesis, Mines ParisTech, 2004.

[22] S. Ravi, V. Balasubramanian, and S. Nemat Nasser. Effect of mismatch ratio on fatigue crack growth behaviour of hsla steel welds. Engineering failure analysis, 21, 2004.

[23] Z. Zhang, D. Delagnes, and G. Bernhart. Anisothermal cyclic plasticity modelling of martensitic steels. International Journal of Fatigue, 24:635-648, 2002.

[24] V. Velay, G. Bernhart, and L. Penazzi. Cyclic behaviour modelling of a tempered martensitic hot work tool steel. International Journal of Plasticity, pages 459-496, 2006. 
[25] L.-P. Chao, Y. Chao, and M. Sutton. Accurate measurements of threedimensional deformations in deformable and rigid bodies using computer vision. Experimental Mechanics, 30:123-132, 1993.

[26] J.-J. Orteu, F. Bugarin, J. Harvent, L. Robert, and V. Velay. Multiplecamera instrumentation of a single point incremental forming process pilot for shape and 3D displacement measurements: Methodology and results. Experimental Mechanics, 51:625-639, 2011.

[27] Vic-3D software. Correlated Solutions Incorporated (C.S.Inc). http://www.correlastedsolutions.com/, 2011.

[28] L. Vincent, S. Calloch, and D. Marquis. A general cyclic plasticity model taking into account yield surface distortion for multiaxial ratchetting. International Journal of Plasticity, 20:1817-1850, 2004.

[29] P. Pilvin. SiDoLo - User Manual. Laboratoire Génie Mécanique et Matériaux, Université de Bretagne-Sud - Rue de Saint-Maudé - BP 92116 - 56321 Lorient cedex - France.

[30] L. Robert, F. Nazaret, T. Cutard, and J.-J. Orteu. Use of 3-D digital image correlation to characterize the mechanical behaviour of a fiber reinforced refractory castable. Experimental Mechanics, 47:761-773, 2007.

[31] O. Ancelet, S. Chapuliot, G. Henaff, and S. Marie. Development of a test for the analysis of the harmfulness of a $3 d$ thermal fatigue loading in tubes. International journal of fatigue, 29:549-564, 2007.

[32] O. Ancelet, S. Chapuliot, and G. Henaff. Experimental and numerical study of crack initiation and propagation under a $3 \mathrm{~d}$ thermal fatigue loading in a welded structure. International journal of fatigue, 30:953-966, 2008.

[33] S. Amiable, S. Chapuliot, A. Constantinescu, and A. Fissolo. A computational lifetime prediction of a thermal shock experiment. part i: thermomechanical modelling and lifetime prediction. J Fatigue Fract Eng Mater Struc, 29:175-182, 2006. 
[34] S. Amiable, S. Chapuliot, A. Constantinescu, and A. Fissolo. A computational lifetime prediction of a thermal shock experiment. part ii: discussion on difference fatigue criteria. J Fatigue Fract Eng Mater Struc, 29:219-228, 2006. 